\title{
Hydroazulene Diterpenes from a Dictyota Brown Alga and Their Antioxidant and Neuroprotective Effects Against Cerebral Ischemia-Reperfusion Injury
}

Jianzhang Wu, ${ }^{\dagger, \perp}$ Yiyuan $\mathrm{Xi},{ }^{\dagger, \perp} \mathrm{Ge}$ Li, ${ }^{\dagger, \perp}$ Yuantie Zheng, ${ }^{\dagger}$ Zhongle Wang, ${ }^{\dagger}$ Jingsong Wang, ${ }^{\dagger}$ Chengyan Fang, ${ }^{\dagger}$ Zhongmin Sun,,${ }^{\ddagger}$ Linya Hu, ${ }^{\dagger}$ Wei Jiang, ${ }^{\S}$ Lishang Dai, ${ }^{\dagger}$ Jianyong Dong, ${ }^{\dagger}$ Peihong Qiu, ${ }^{\dagger}$ Min Zhao,,${ }^{*}$ and Pengcheng Yan ${ }^{*}, \dagger$

†School of Pharmaceutical Sciences, Wenzhou Medical University, Wenzhou, Zhejiang 325035, People's Republic of China

\$nstitute of Oceanology, Chinese Academy of Sciences, Qingdao 266071, People’s Republic of China.

${ }^{\S}$ School of Environmental Science and Engineering, Yangzhou University, Yangzhou, Jiangsu 225127, People's Republic of China

\section{Corresponding Authors}

${ }^{*}$ Tel (P. Yan): +86-577-86699572; E-mail: yanpc@wmu.edu.cn

*E-mail (M. Zhao): zhaomin@wmu.edu.cn

Author Contributions

${ }^{\perp}$ J. Wu, Y. Xi, and G. Li made equal contributions to this work. 


\section{List of supporting information}

Figure S1. ${ }^{1} \mathrm{H}$ NMR spectrum $(600 \mathrm{MHz})$ of compound 1 in acetone- $d_{6}$.

Figure S2. ${ }^{13} \mathrm{C}$ NMR spectrum $(150 \mathrm{MHz})$ of compound 1 in acetone- $d_{6}$.

Figure S3. HMQC spectrum of compound 1 in acetone- $d_{6}$.

Figure S4. HMBC spectrum of compound 1 in acetone- $d_{6}$.

Figure S5. COSY spectrum of compound 1 in acetone- $d_{6}$.

Figure S6. NOESY spectrum of compound 1 in acetone- $d_{6}$.

Figure S7. HRESIMS spectrum of compound 1 .

Figure S8. ${ }^{1} \mathrm{H}$ NMR spectrum $(600 \mathrm{MHz})$ of compound 2 in acetone- $d_{6}$.

Figure S9. ${ }^{13} \mathrm{C}$ NMR spectrum $(150 \mathrm{MHz})$ of compound 2 in acetone- $d_{6}$.

Figure S10. HMQC spectrum of compound 2 in acetone- $d_{6}$.

Figure S11. HMBC spectrum of compound 2 in acetone- $d_{6}$.

Figure S12. COSY spectrum of compound 2 in acetone- $d_{6}$.

Figure S13. NOESY spectrum of compound 2 in acetone- $d_{6}$.

Figure S14. HRESIMS spectrum of compound 2.

Figure S15. ${ }^{1} \mathrm{H}$ NMR spectrum $(600 \mathrm{MHz})$ of compound 3 in acetone- $d_{6}$.

Figure S16. ${ }^{13} \mathrm{C}$ NMR spectrum $(150 \mathrm{MHz})$ of compound 3 in acetone- $d_{6}$.

Figure S17. HMQC spectrum of compound 3 in acetone- $d_{6}$.

Figure S18. HMBC spectrum of compound 3 in acetone- $d_{6}$.

Figure S19. COSY spectrum of compound 3 in acetone- $d_{6}$.

Figure S20. NOESY spectrum of compound $\mathbf{3}$ in acetone- $d_{6}$.

Figure S21. HRESIMS spectrum of compound 3.

Figure S22. ${ }^{1} \mathrm{H}$ NMR spectrum $(500 \mathrm{MHz})$ of compound 4 in acetone- $d_{6}$.

Figure S23. ${ }^{13} \mathrm{C}$ NMR spectrum $(125 \mathrm{MHz})$ of compound 4 in acetone- $d_{6}$.

Figure S24. HMQC spectrum of compound 4 in acetone- $d_{6}$.

Figure S25. HMBC spectrum of compound 4 in acetone- $d_{6}$.

Figure S26. COSY spectrum of compound 4 in acetone- $d_{6}$.

Figure S27. NOESY spectrum of compound 4 in acetone- $d_{6}$.

Figure S28. HRESIMS spectrum of compound 4.

Figure S29. ${ }^{1} \mathrm{H}$ NMR spectrum $(500 \mathrm{MHz})$ of compound 5 in acetone- $d_{6}$. 
Figure S30. ${ }^{13} \mathrm{C}$ NMR spectrum $(125 \mathrm{MHz})$ of compound 5 in acetone- $d_{6}$.

Figure S31. HMQC spectrum of compound 5 in acetone- $d_{6}$.

Figure S32. HMBC spectrum of compound 5 in acetone- $d_{6}$.

Figure S33. COSY spectrum of compound 5 in acetone- $d_{6}$.

Figure S34. NOESY spectrum of compound 5 in acetone- $d_{6}$.

Figure S35. HRESIMS spectrum of compound 5.

Figure S36. CD spectrum for $\mathrm{Rh}_{2}\left(\mathrm{OCOCF}_{3}\right)_{4}$ complex of compound $\mathbf{1}$.

Figure S37. ${ }^{1} \mathrm{H}$ NMR spectrum $(500 \mathrm{MHz})$ of compound 6 in acetone- $d_{6}$.

Figure S38. ${ }^{13} \mathrm{C}$ NMR spectrum $(125 \mathrm{MHz})$ of compound 6 in acetone- $d_{6}$.

Figure S39. ${ }^{1} \mathrm{H}$ NMR spectrum $(600 \mathrm{MHz})$ of compound 7 in $\mathrm{CDCl}_{3}$.

Figure S40. ${ }^{13} \mathrm{C}$ NMR spectrum $(150 \mathrm{MHz})$ of compound 7 in $\mathrm{CDCl}_{3}$.

Figure S41. ${ }^{1} \mathrm{H}$ NMR spectrum $(600 \mathrm{MHz})$ of compound 8 in acetone- $d_{6}$.

Figure S42. ${ }^{13} \mathrm{C}$ NMR spectrum $(150 \mathrm{MHz})$ of compound 8 in acetone- $d_{6}$.

Figure S43. ${ }^{1} \mathrm{H}$ NMR spectrum $(600 \mathrm{MHz})$ of compound 9 in acetone- $d_{6}$.

Figure S44. ${ }^{13} \mathrm{C}$ NMR spectrum $(150 \mathrm{MHz})$ of compound 9 in acetone- $d_{6}$.

Figure S45. ${ }^{1} \mathrm{H}$ NMR spectrum $(600 \mathrm{MHz})$ of compound 10 in acetone- $d_{6}$.

Figure S46. ${ }^{13} \mathrm{C}$ NMR spectrum $(150 \mathrm{MHz})$ of compound 10 in acetone- $d_{6}$.

Figure S47. The cytoprotection of EtOAc extract of Dictyota sp. nov. on PC12 cells in the $\mathrm{H}_{2} \mathrm{O}_{2}$ damage model.

Table S1. ${ }^{1} \mathrm{H}$ NMR data for compounds 6-10.

Table S2. ${ }^{13} \mathrm{C}$ NMR data for compounds 6-10.

Table S3. DNA sequence of the alga specimen (Dictyota sp. nov.) 
Figure S1. ${ }^{1} \mathrm{H}$ NMR spectrum $(600 \mathrm{MHz})$ of compound 1 in acetone- $d_{6}$. XY01D079B, 1H, Acetone-d6, 600MHz

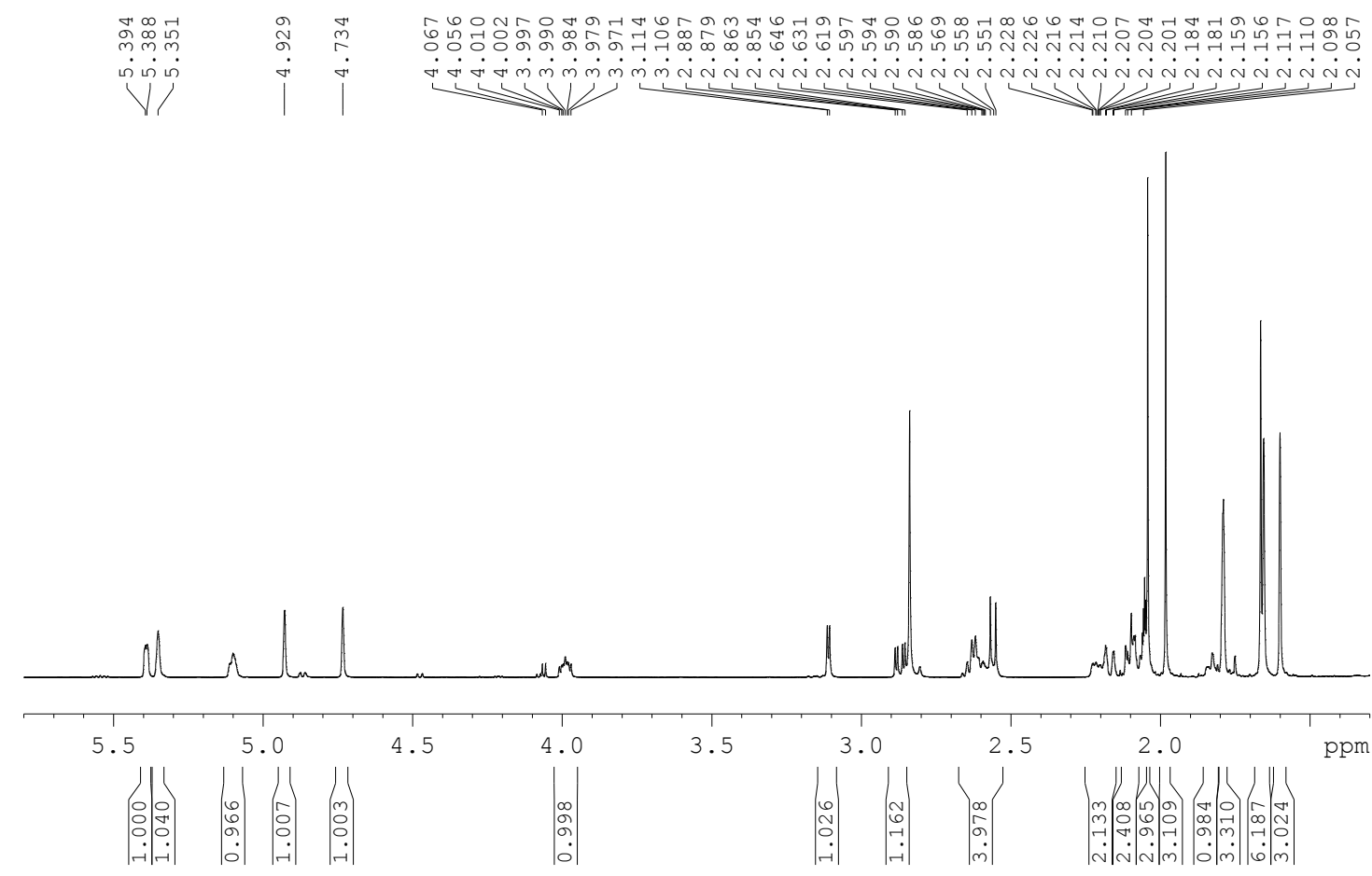

Figure S2. ${ }^{13} \mathrm{C}$ NMR spectrum $(150 \mathrm{MHz})$ of compound 1 in acetone- $d_{6}$.

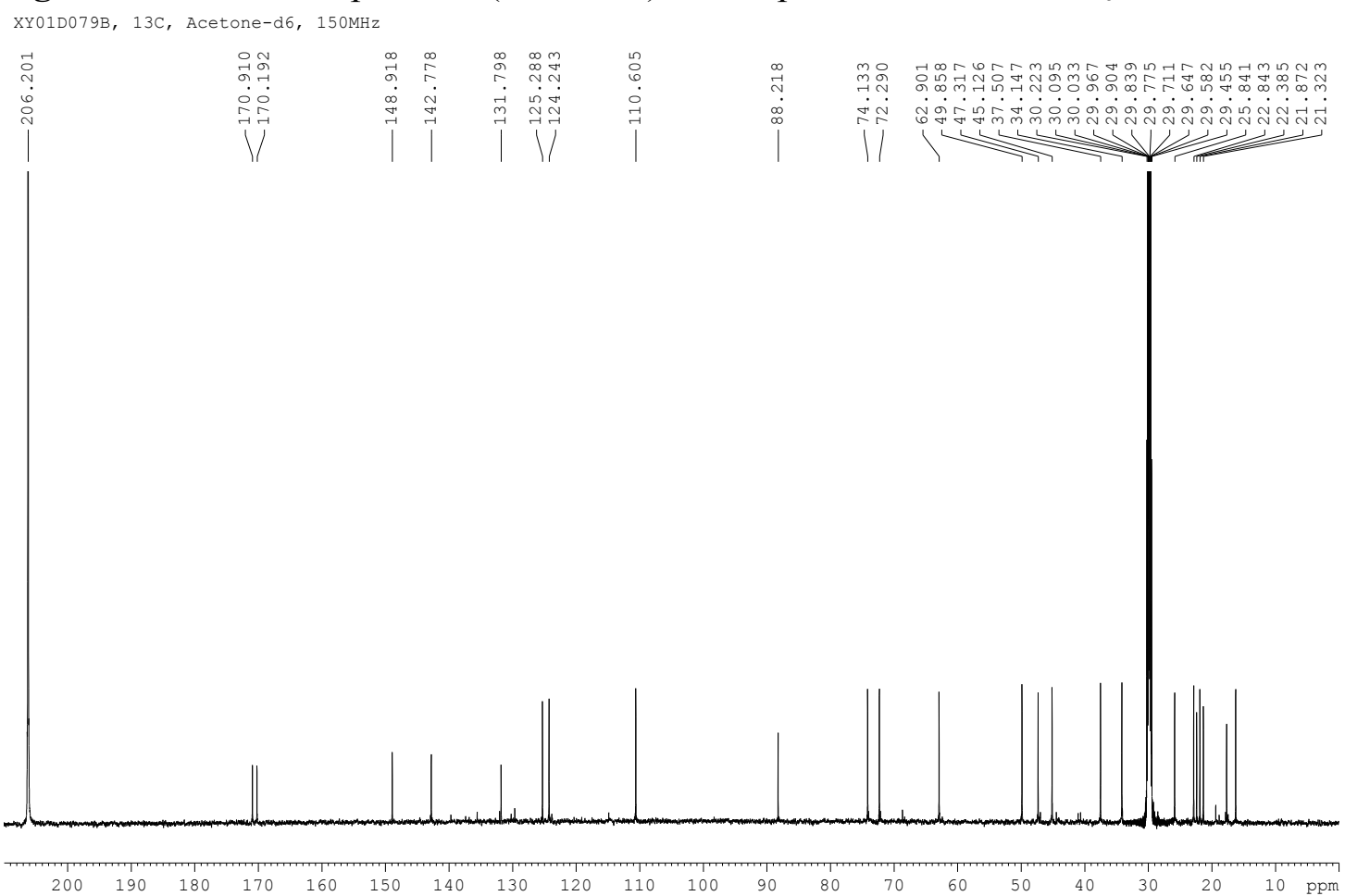


Figure S3. HMQC spectrum of compound 1 in acetone- $d_{6}$.

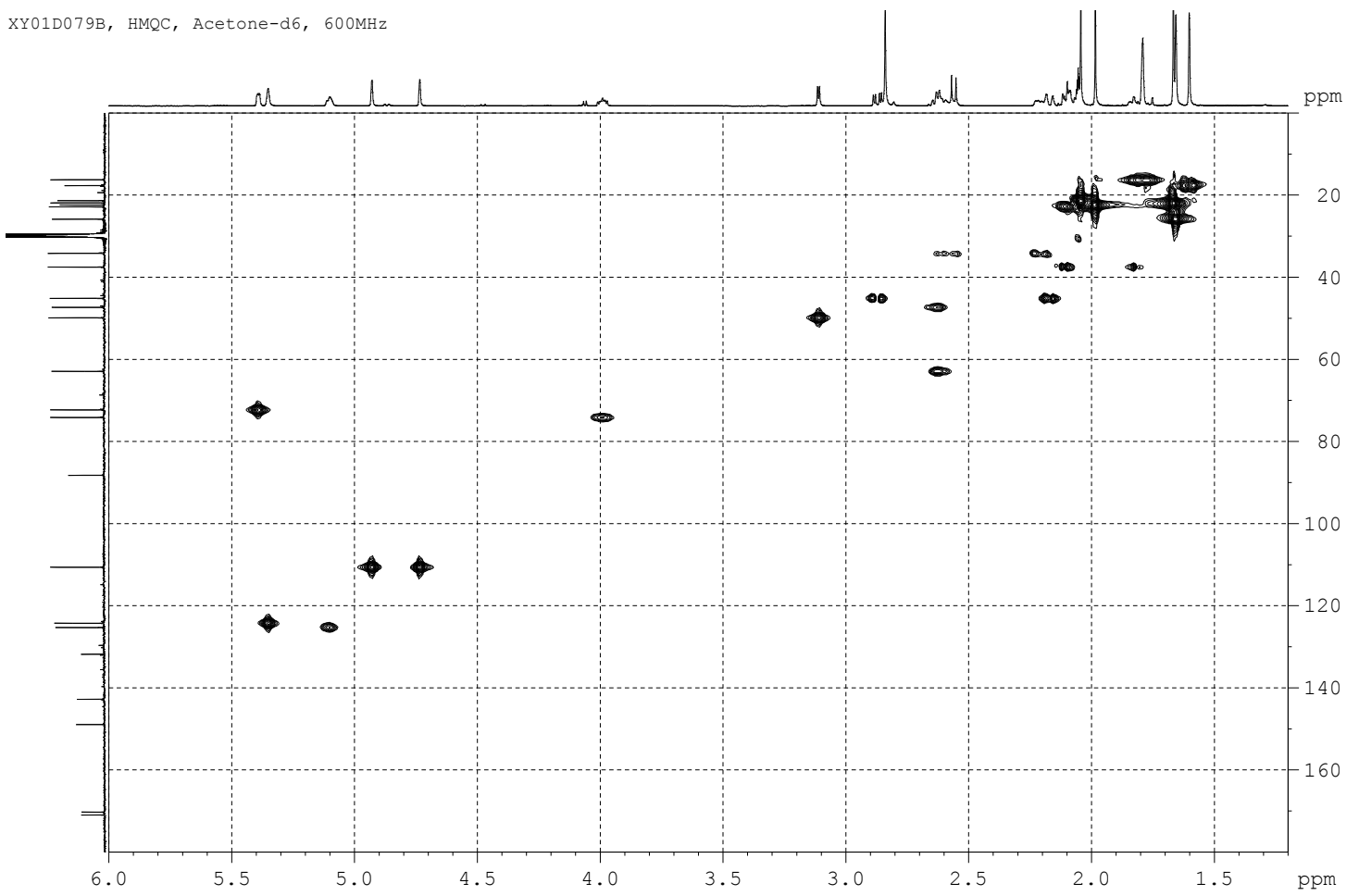

Figure S4. HMBC spectrum of compound 1 in acetone- $d_{6}$.

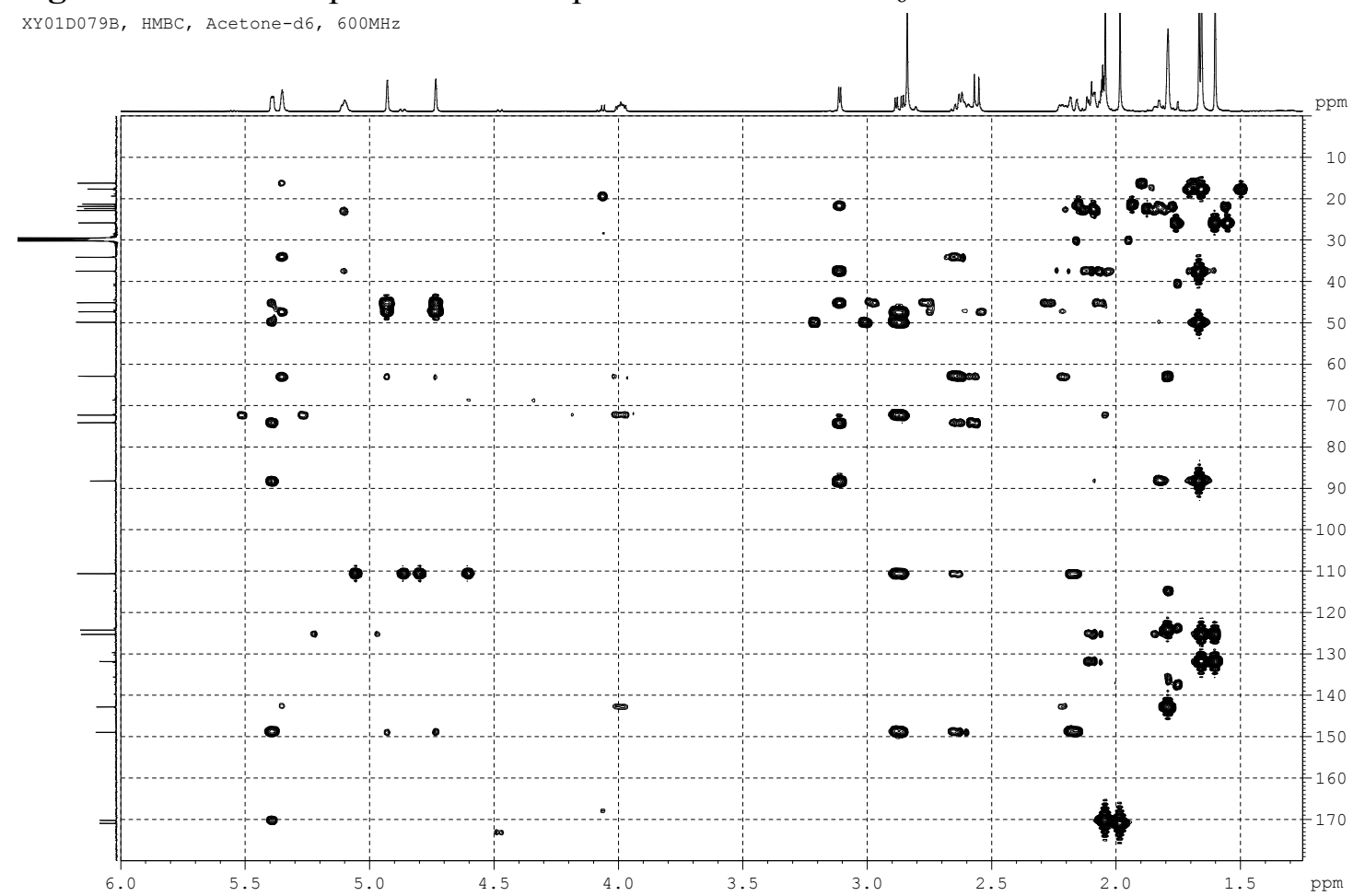


Figure S5. COSY spectrum of compound $\mathbf{1}$ in acetone- $d_{6}$.

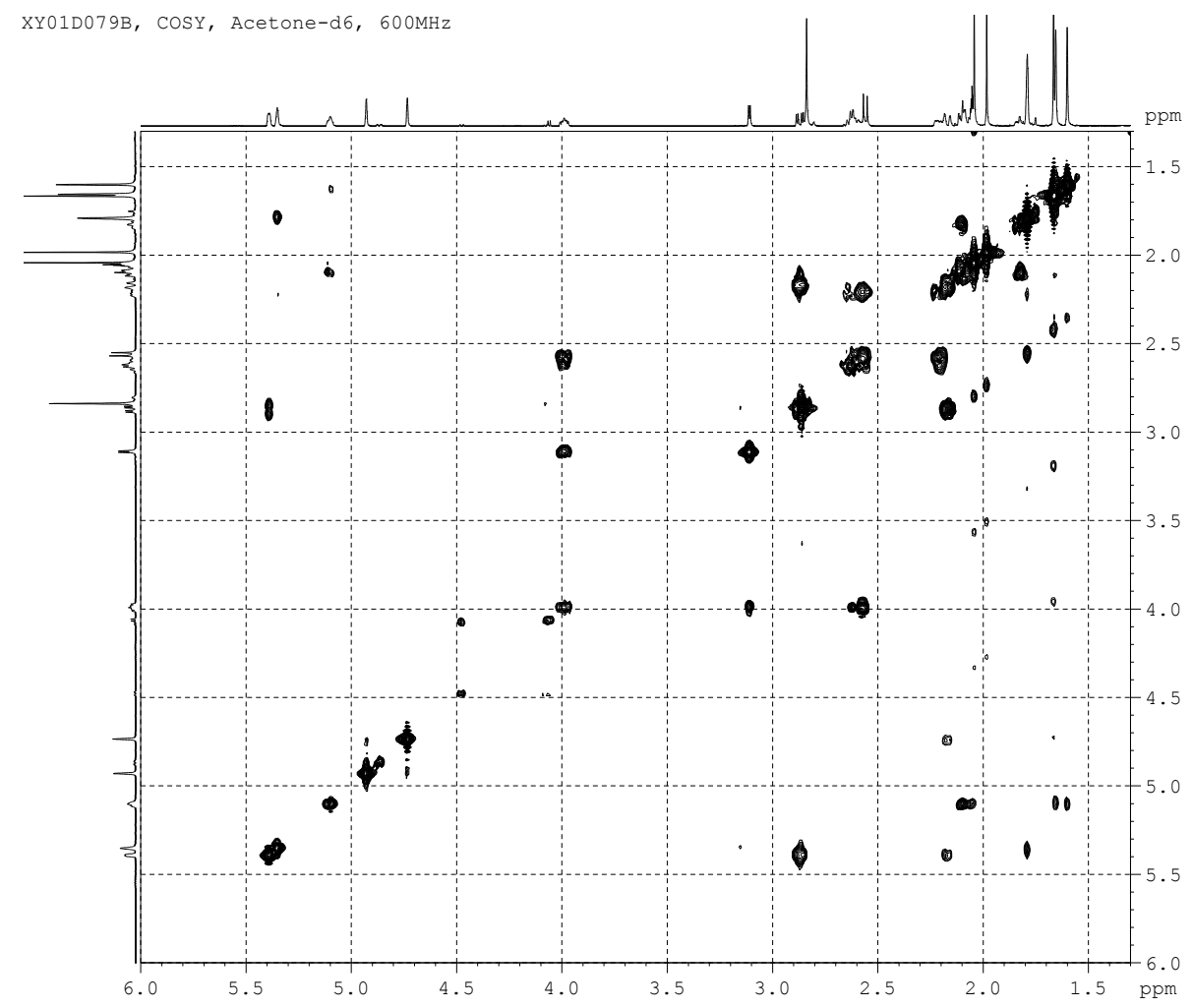

Figure S6. NOESY spectrum of compound 1 in acetone- $d_{6}$.

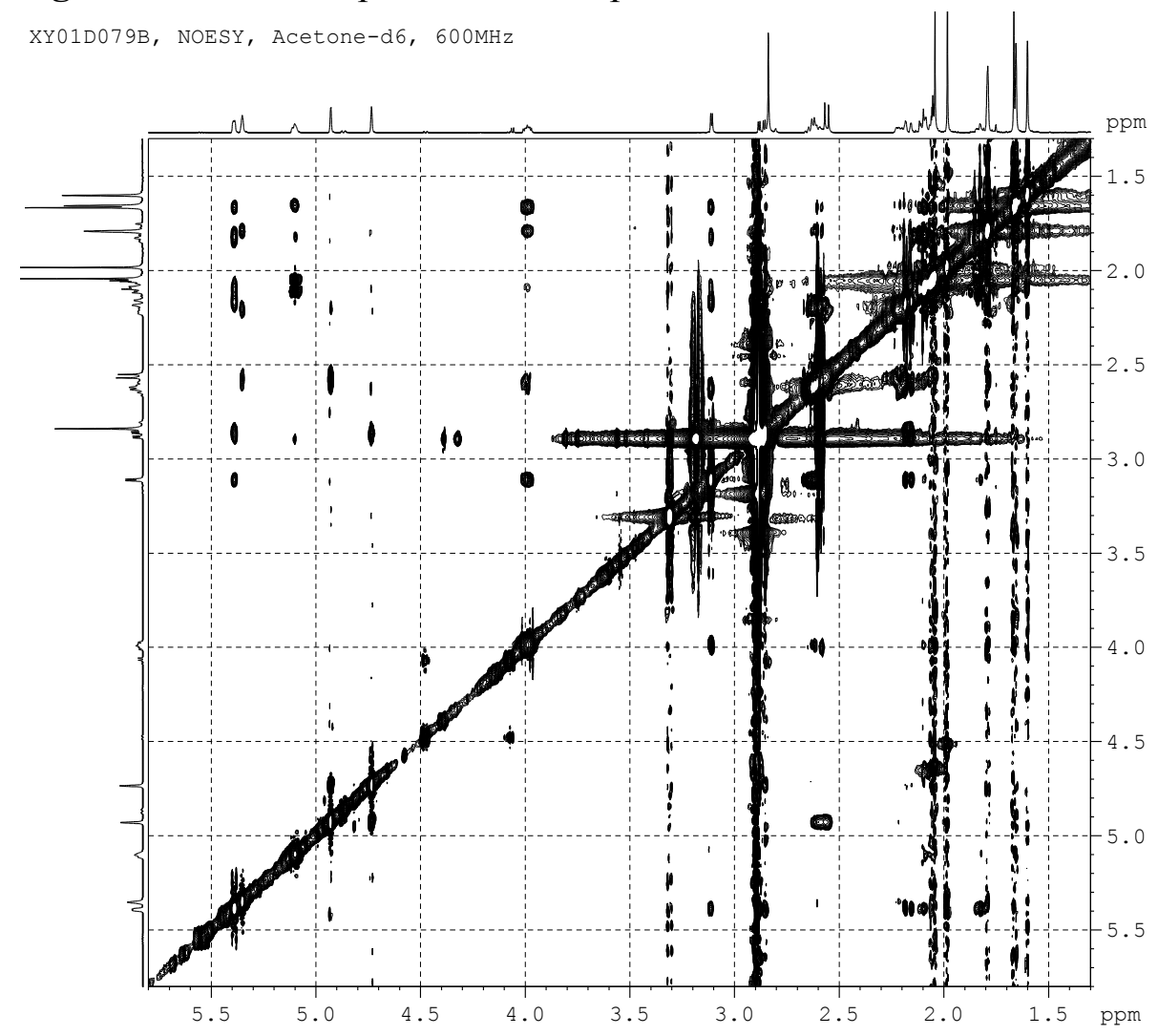


Figure S7. HRESIMS spectrum of compound 1.

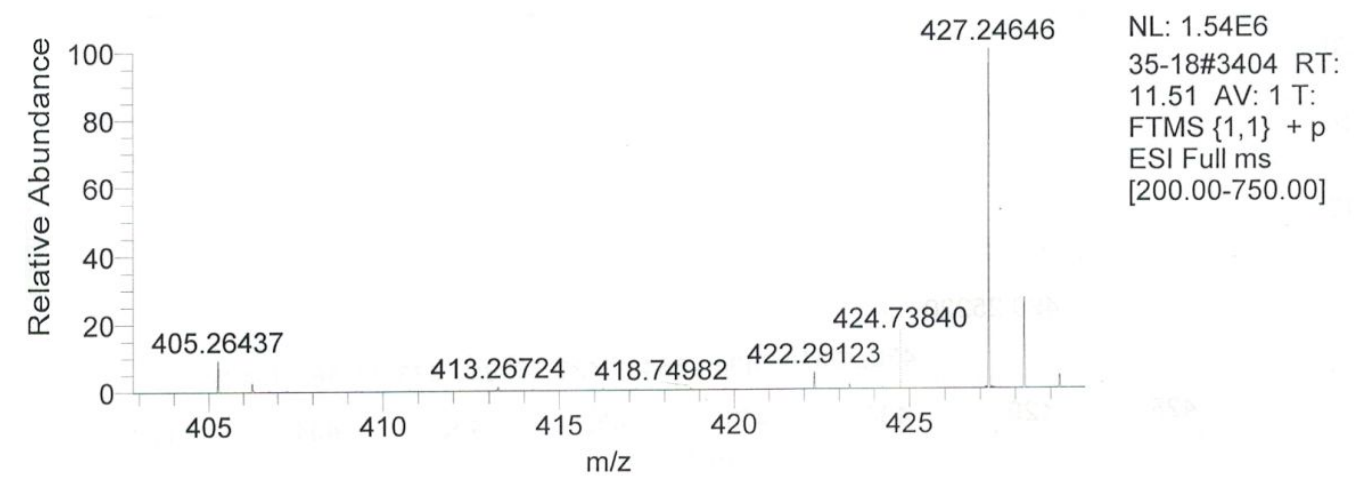

Figure S8. ${ }^{1} \mathrm{H}$ NMR spectrum $(600 \mathrm{MHz})$ of compound 2 in acetone- $d_{6}$. XY01D079C, 1H, Acetone-d6, 600MHz

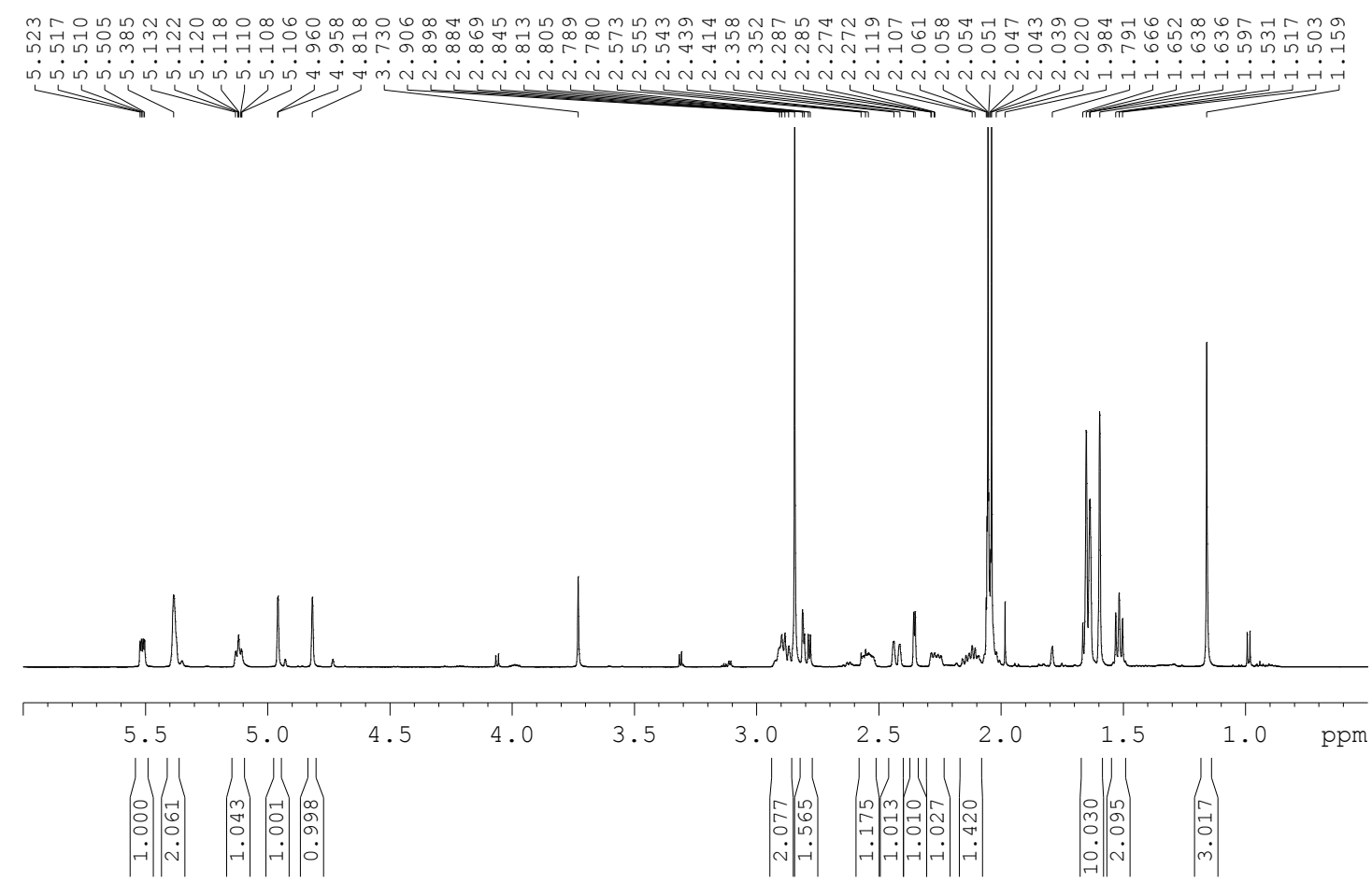


Figure S9. ${ }^{13} \mathrm{C}$ NMR spectrum $(150 \mathrm{MHz})$ of compound 2 in acetone- $d_{6}$.

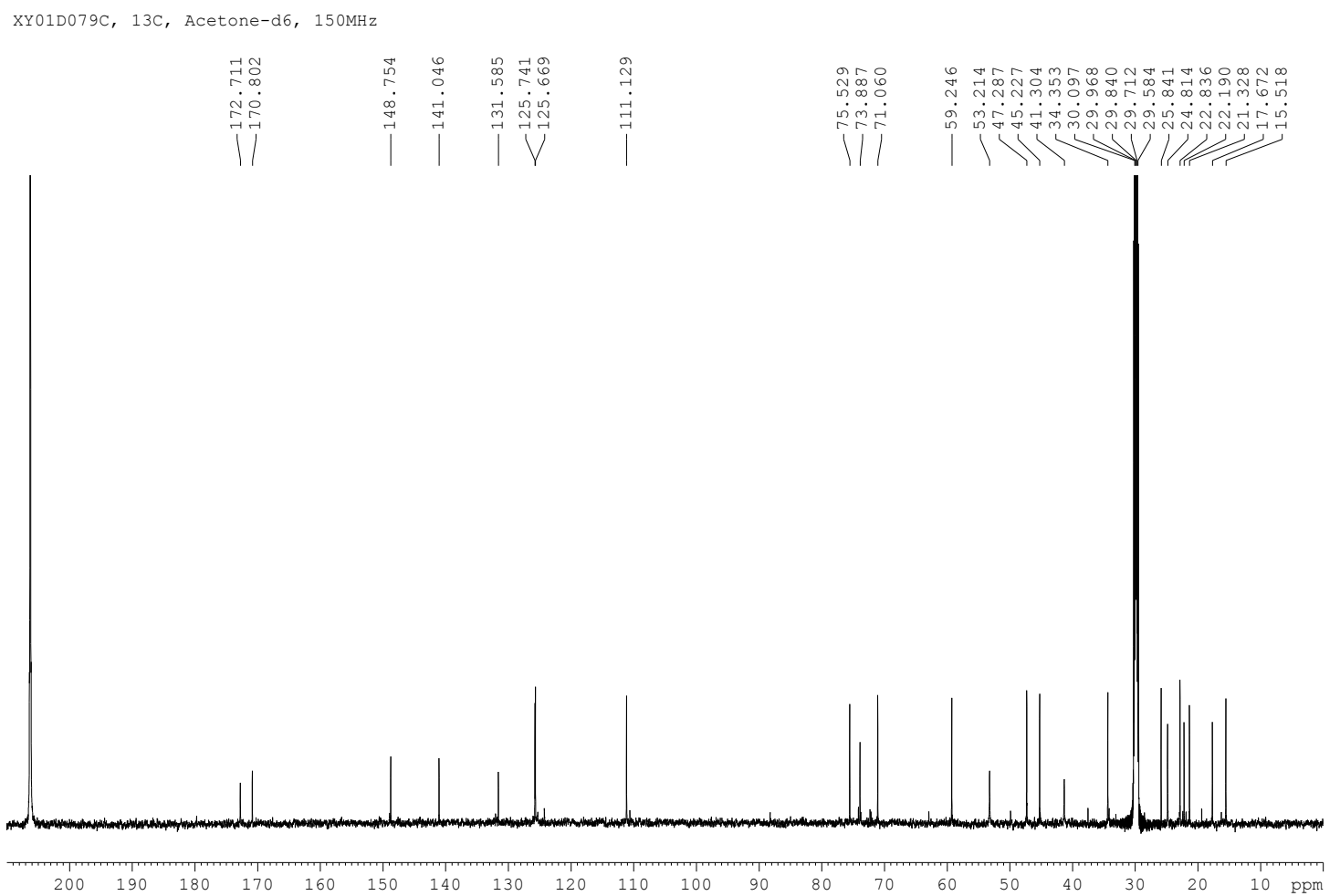

Figure S10. HMQC spectrum of compound 2 in acetone- $d_{6}$.

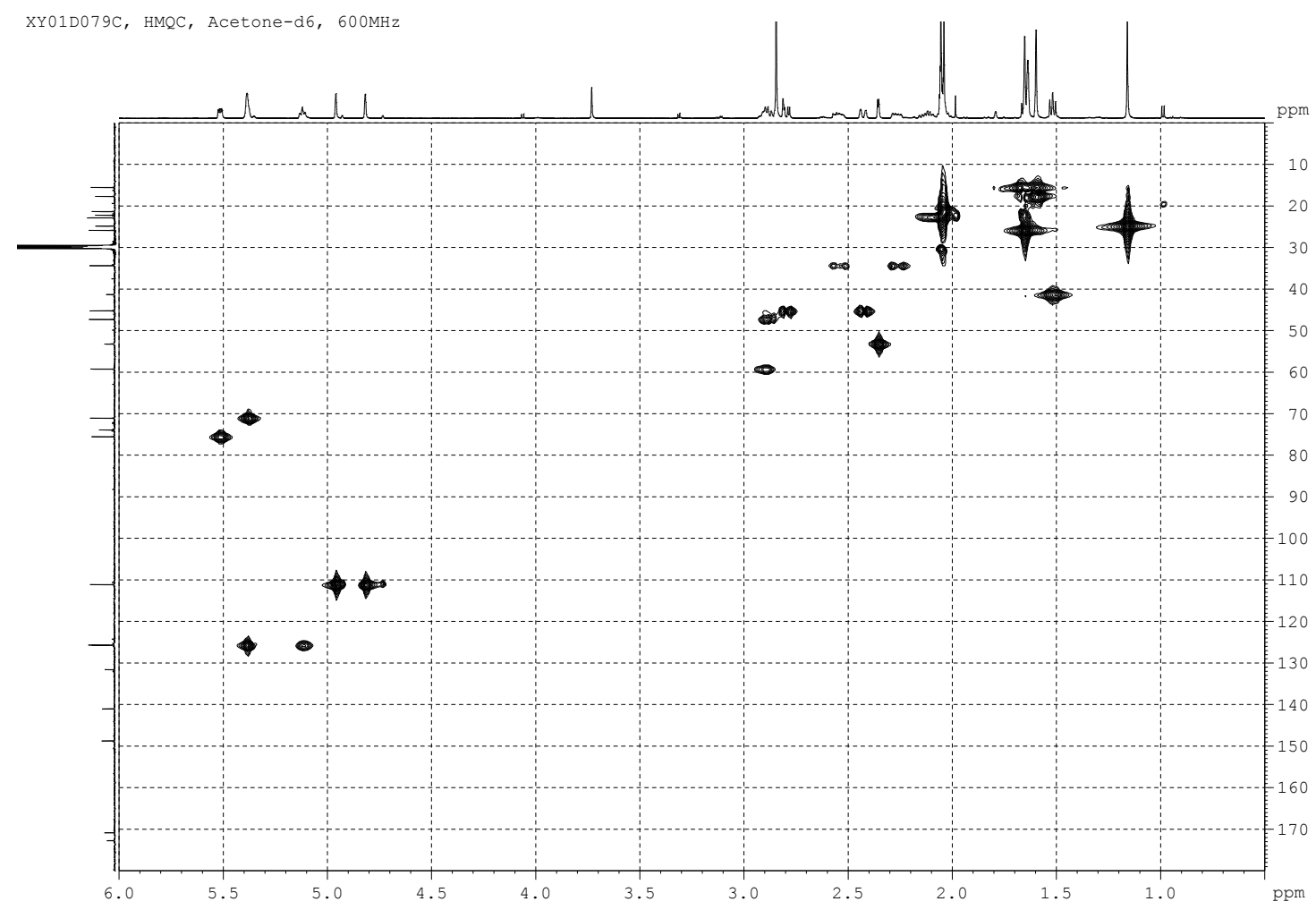


Figure S11. HMBC spectrum of compound $\mathbf{2}$ in acetone- $d_{6}$.

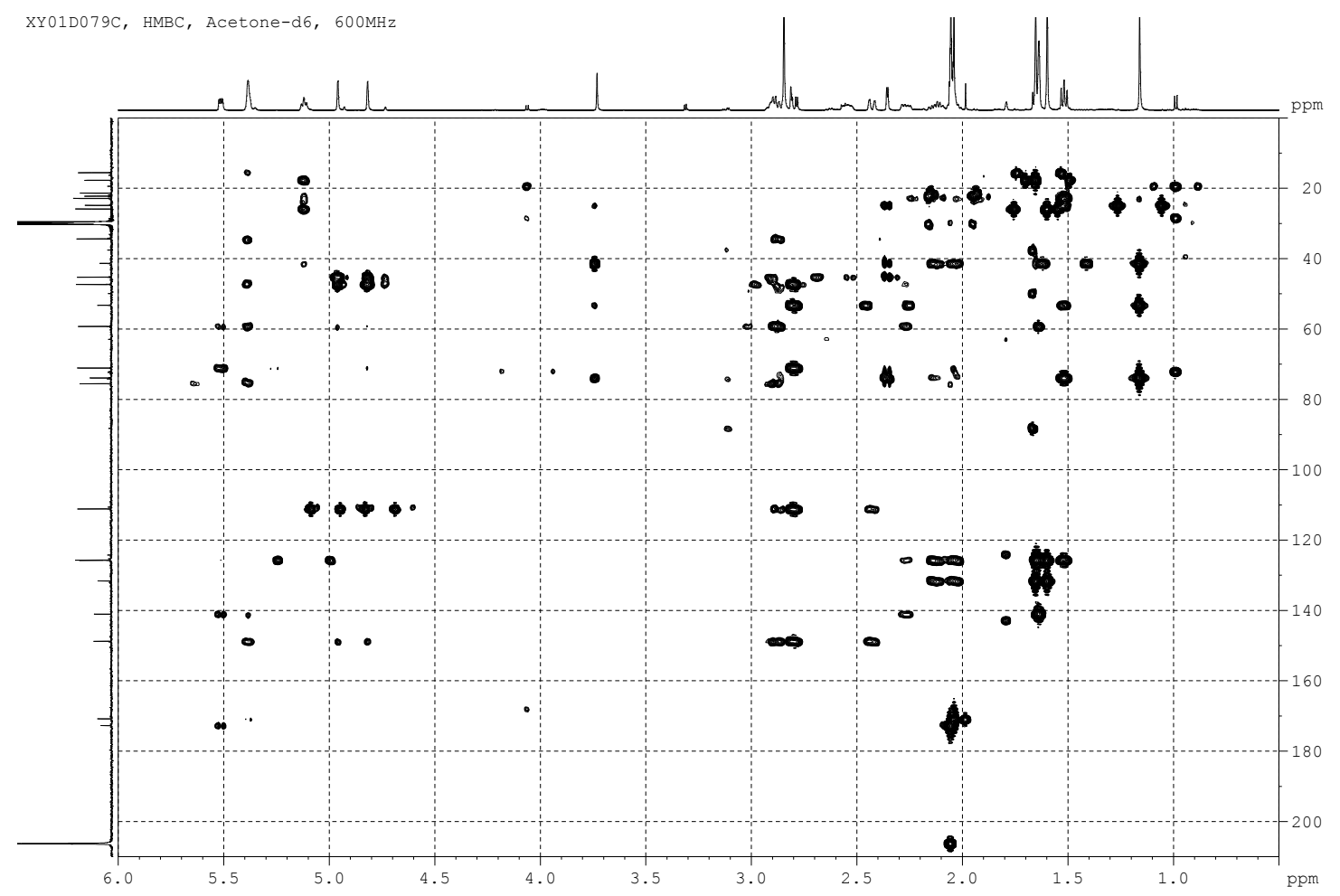

Figure S12. COSY spectrum of compound 2 in acetone- $d_{6}$.

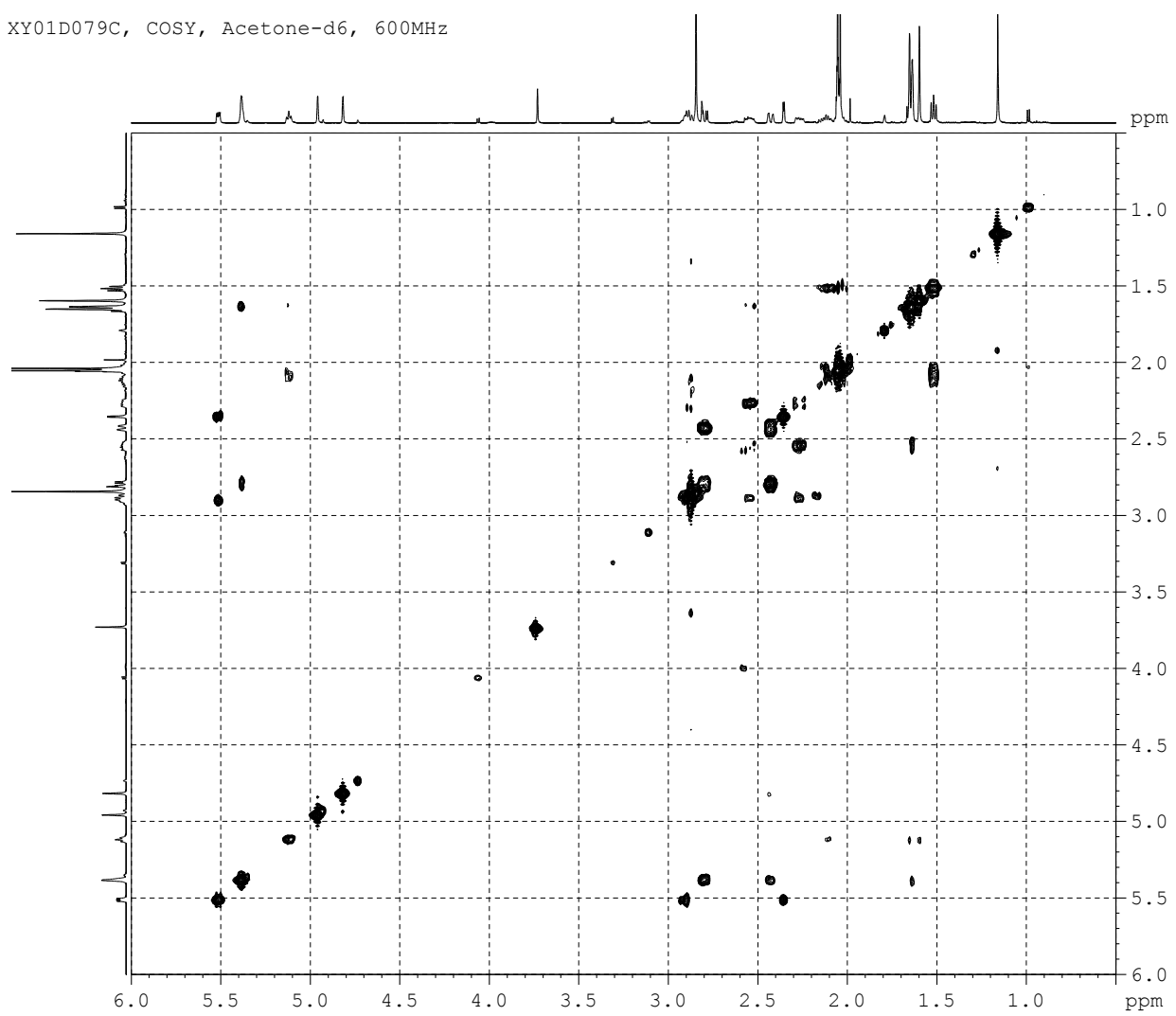


Figure S13. NOESY spectrum of compound 2 in acetone- $d_{6}$.

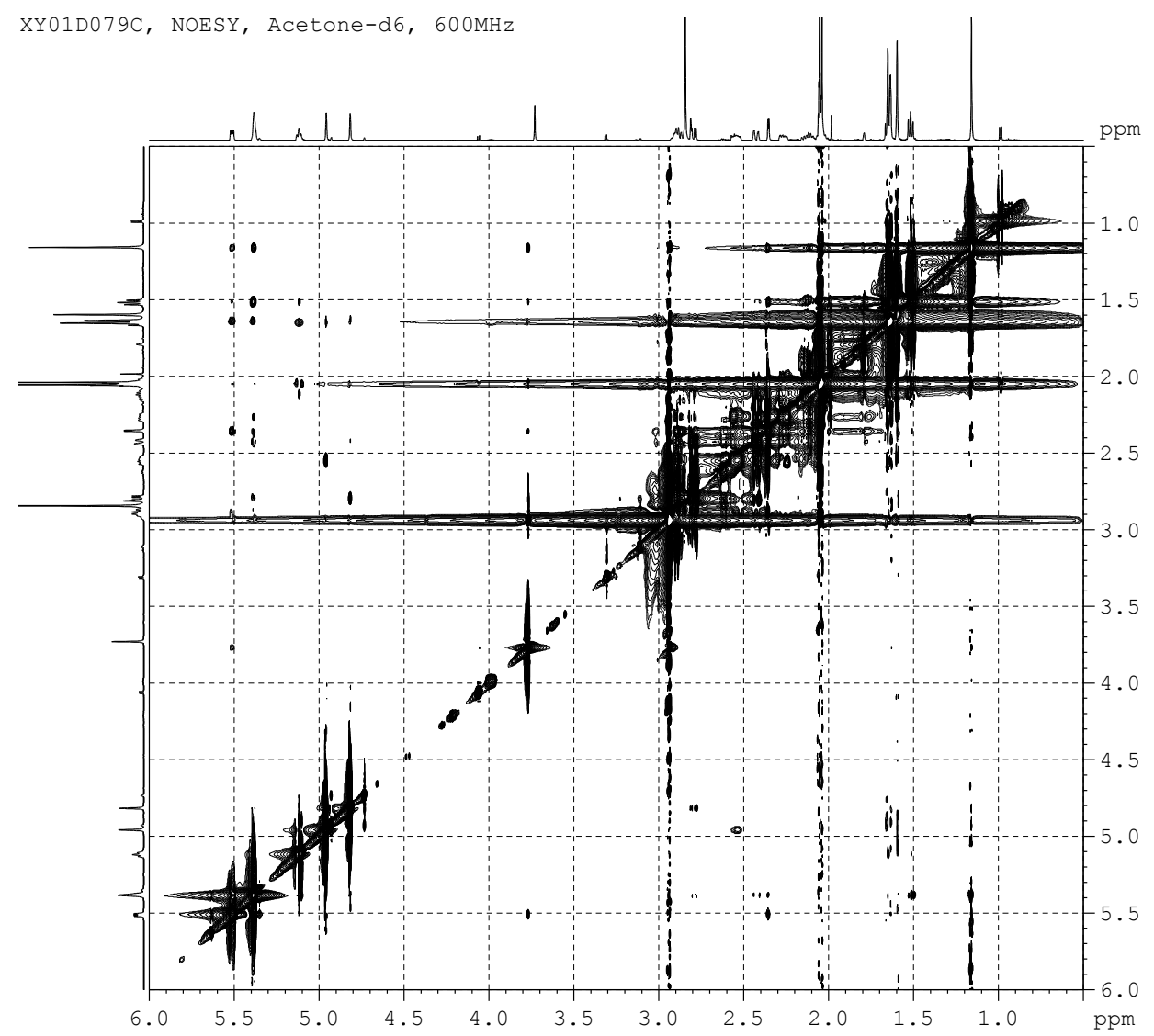

Figure S14. HRESIMS spectrum of compound 2.

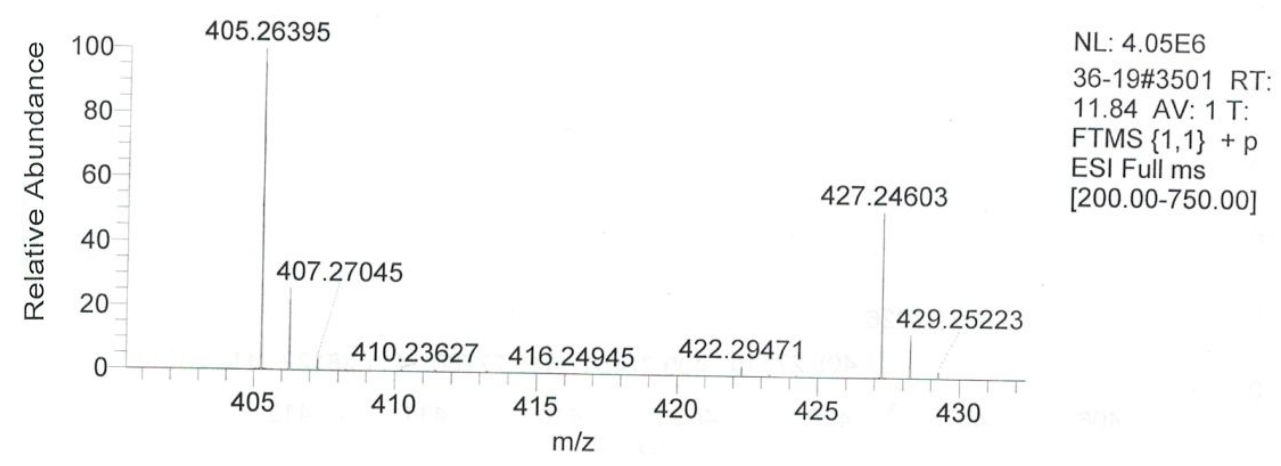


Figure S15. ${ }^{1} \mathrm{H}$ NMR spectrum $(600 \mathrm{MHz})$ of compound 3 in acetone- $d_{6}$. XY01D079A, 1H, Acetone-d6, 600MHz

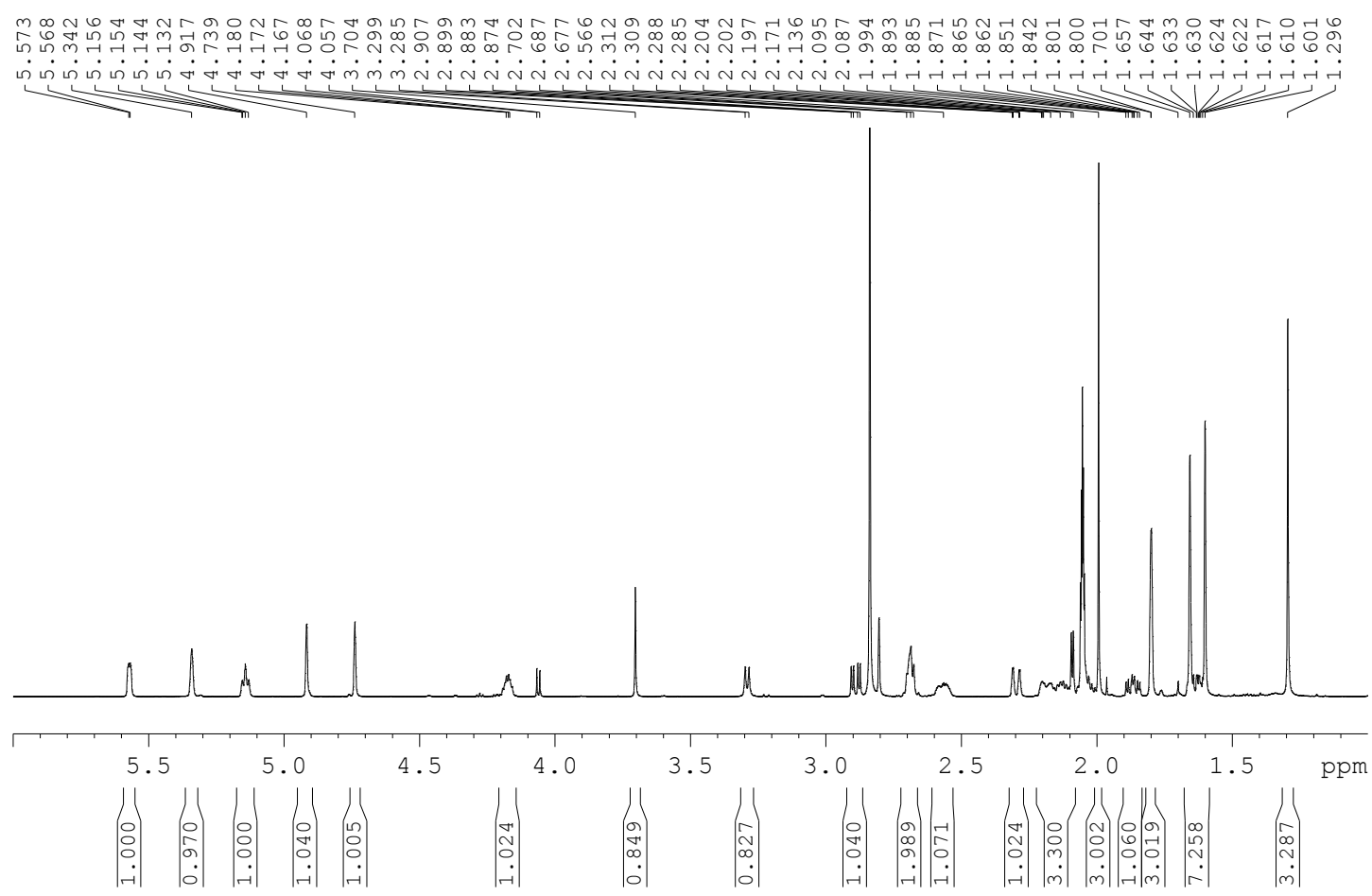

Figure S16. ${ }^{13} \mathrm{C}$ NMR spectrum $(150 \mathrm{MHz})$ of compound 3 in acetone- $d_{6}$.

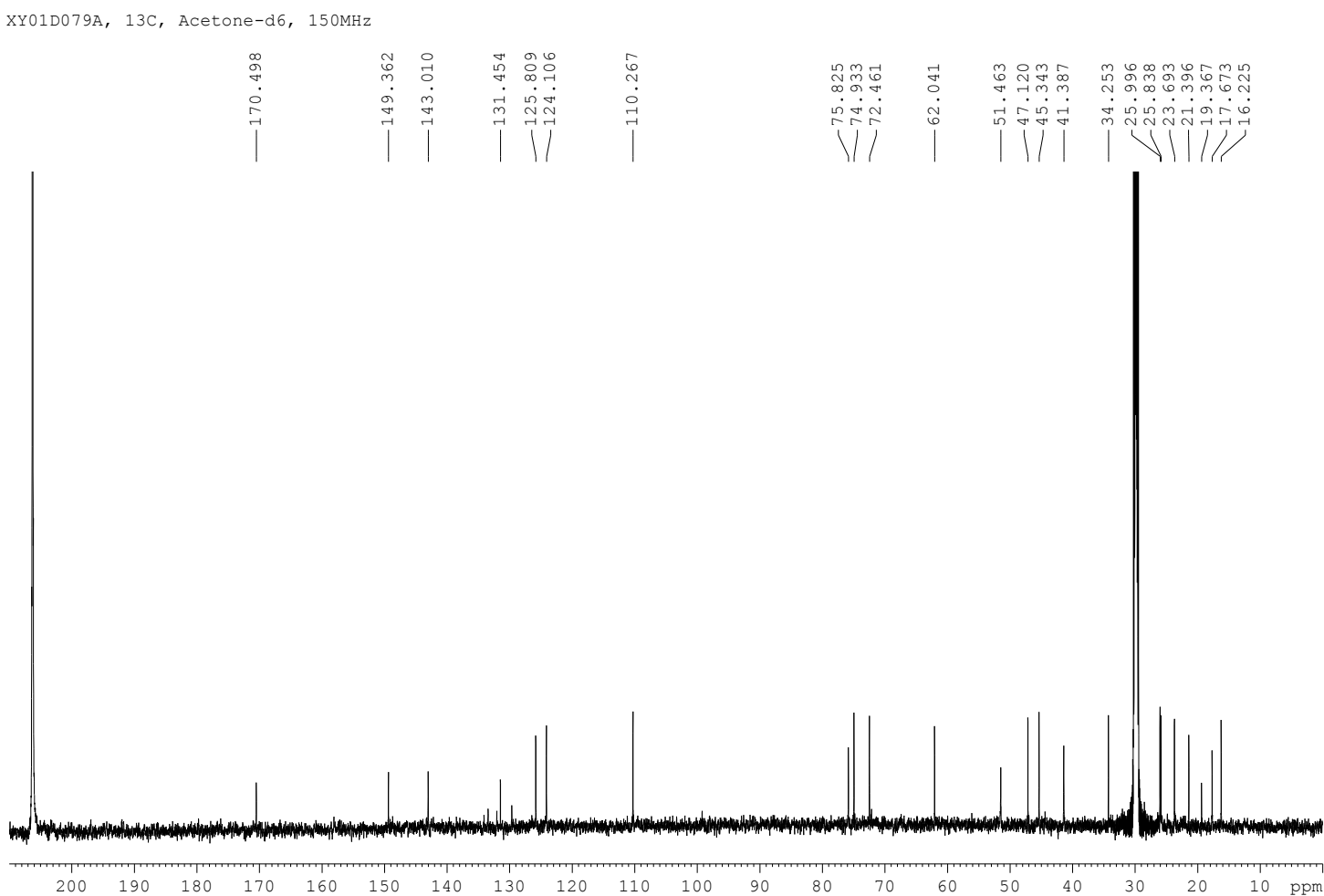


Figure S17. HMQC spectrum of compound 3 in acetone- $d_{6}$.

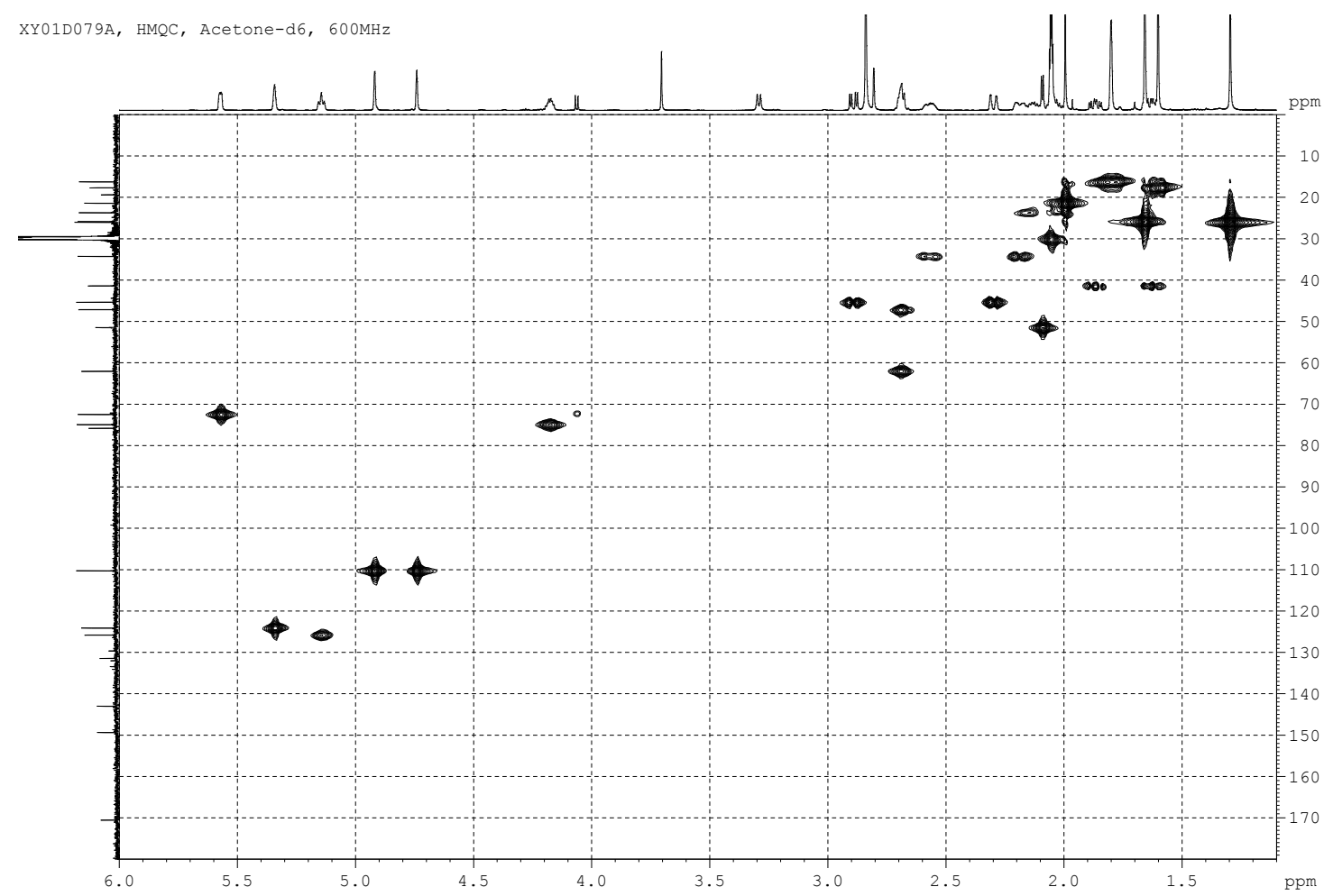

Figure S18. HMBC spectrum of compound 3 in acetone- $d_{6}$.

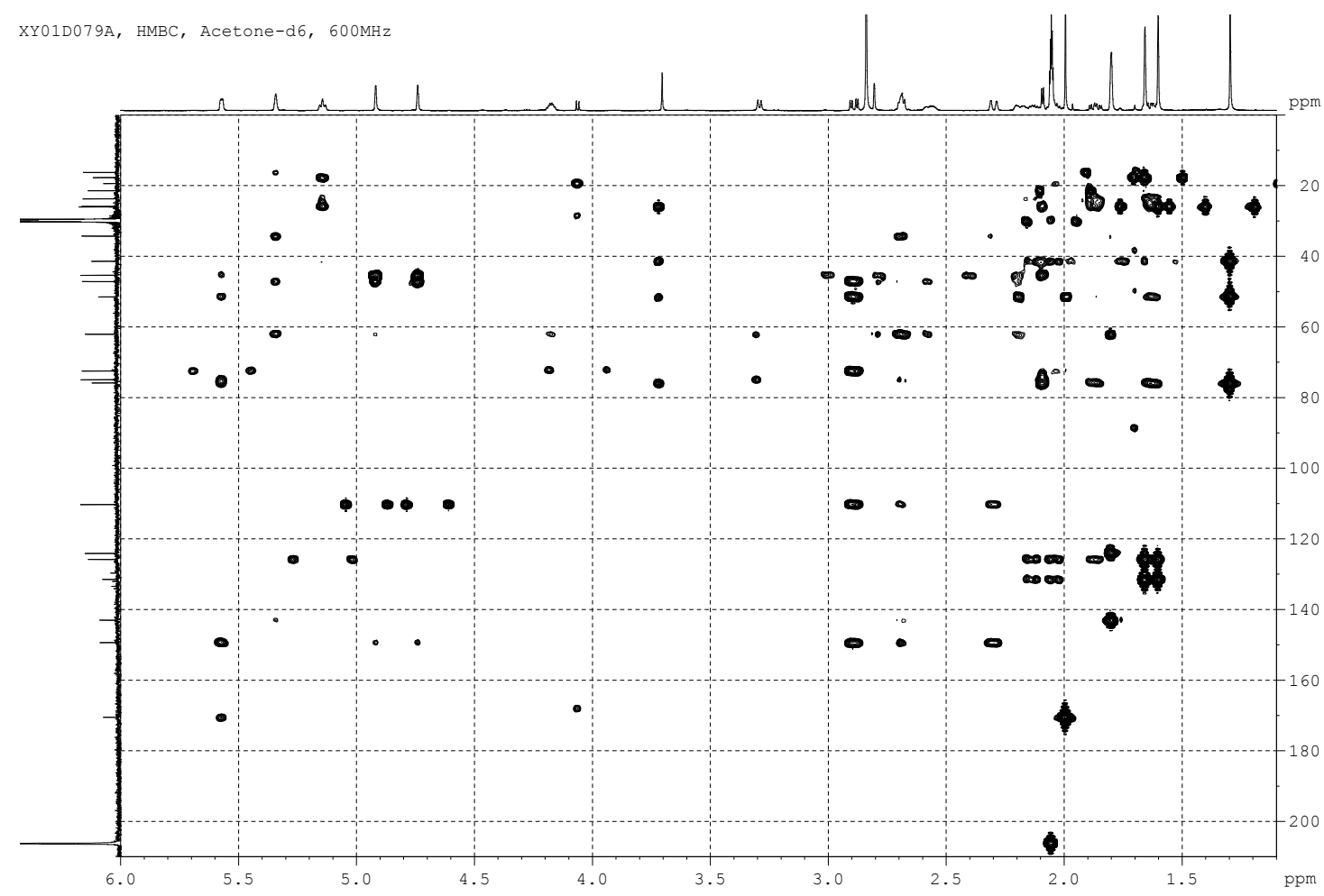


Figure S19. COSY spectrum of compound 3 in acetone- $d_{6}$.

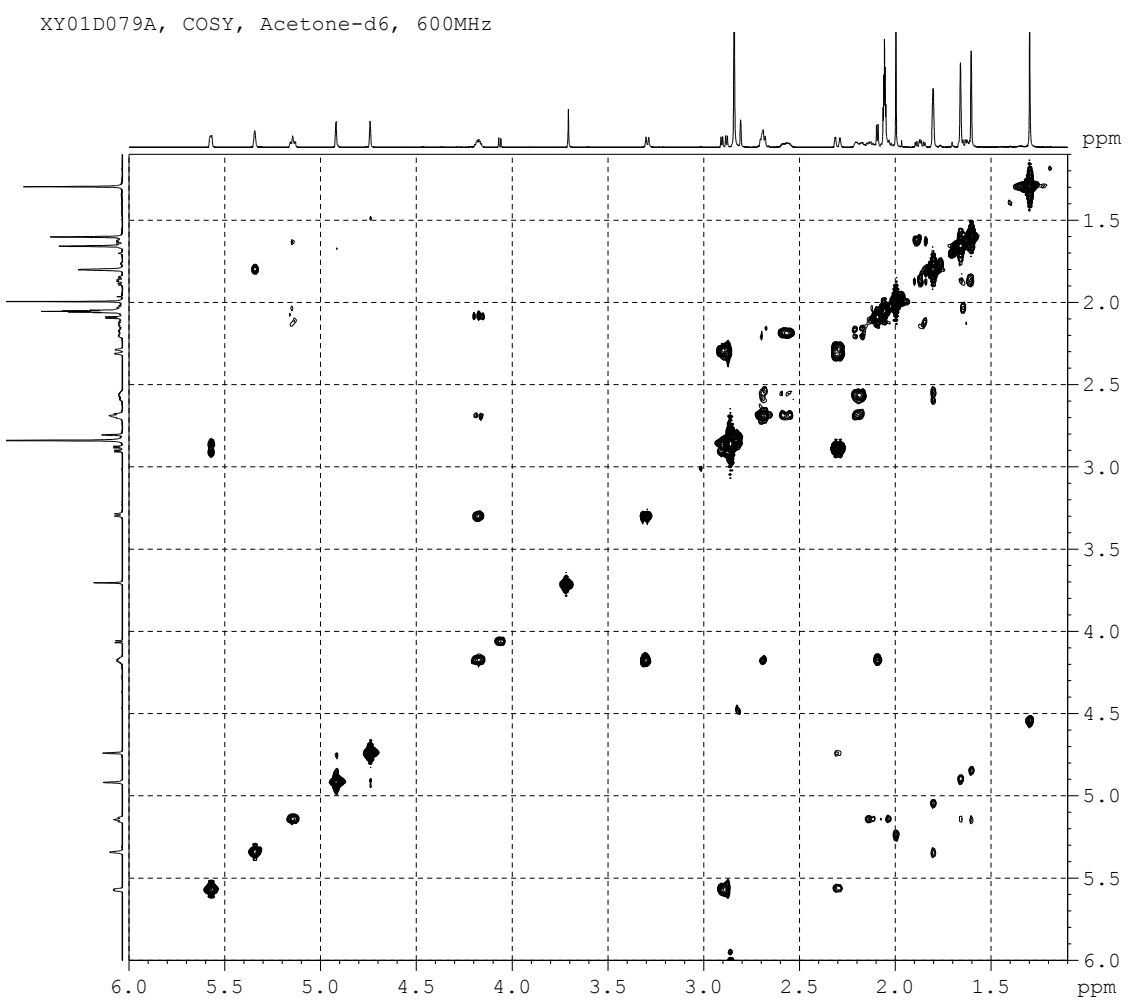

Figure S20. NOESY spectrum of compound 3 in acetone- $d_{6}$.

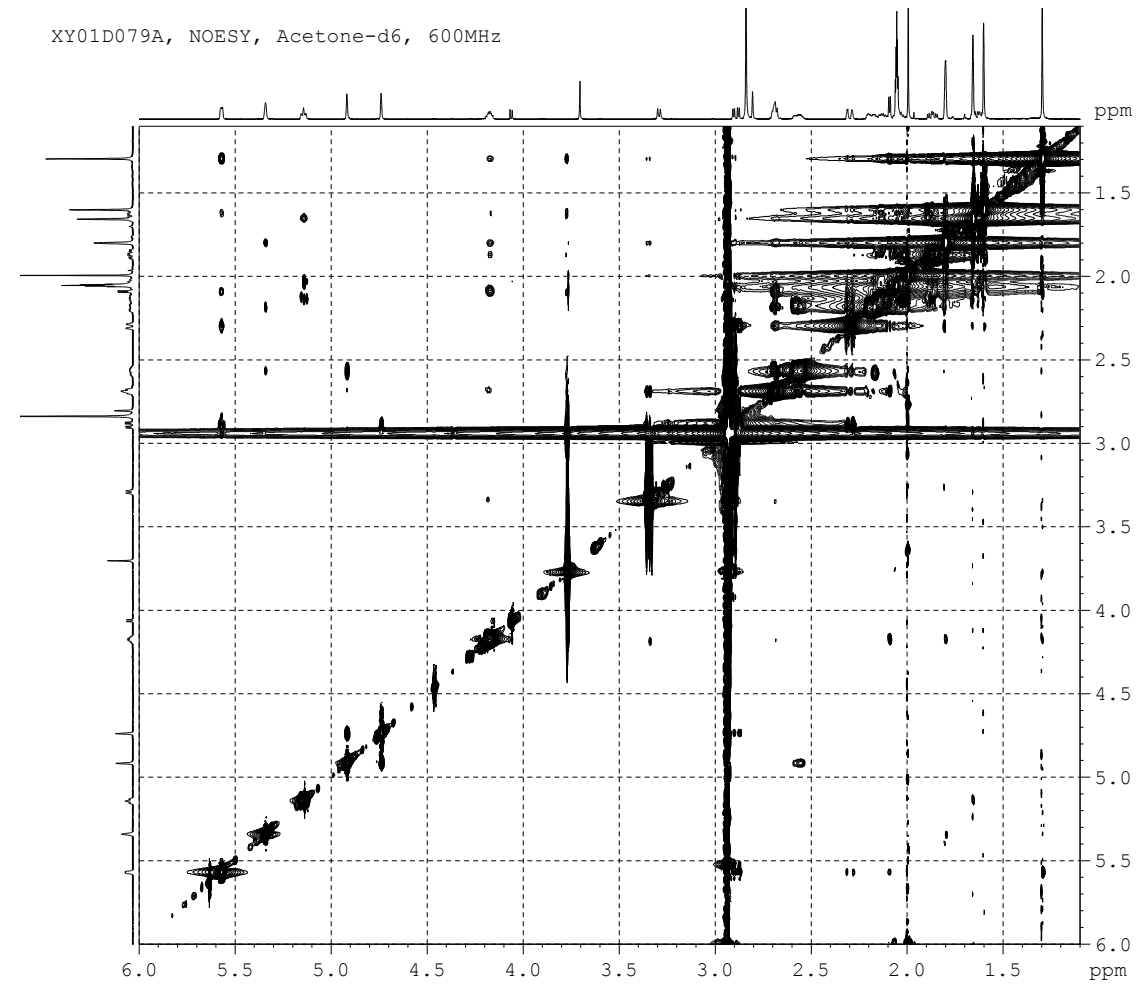


Figure S21. HRESIMS spectrum of compound 3.

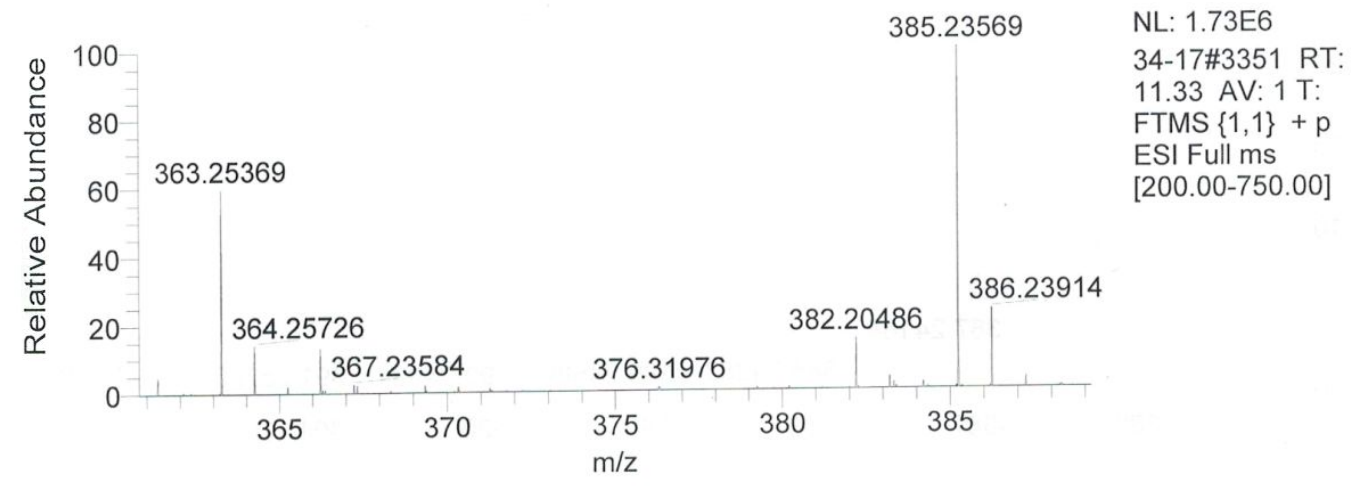

Figure S22. ${ }^{1} \mathrm{H}$ NMR spectrum $(500 \mathrm{MHz})$ of compound 4 in acetone- $d_{6}$.

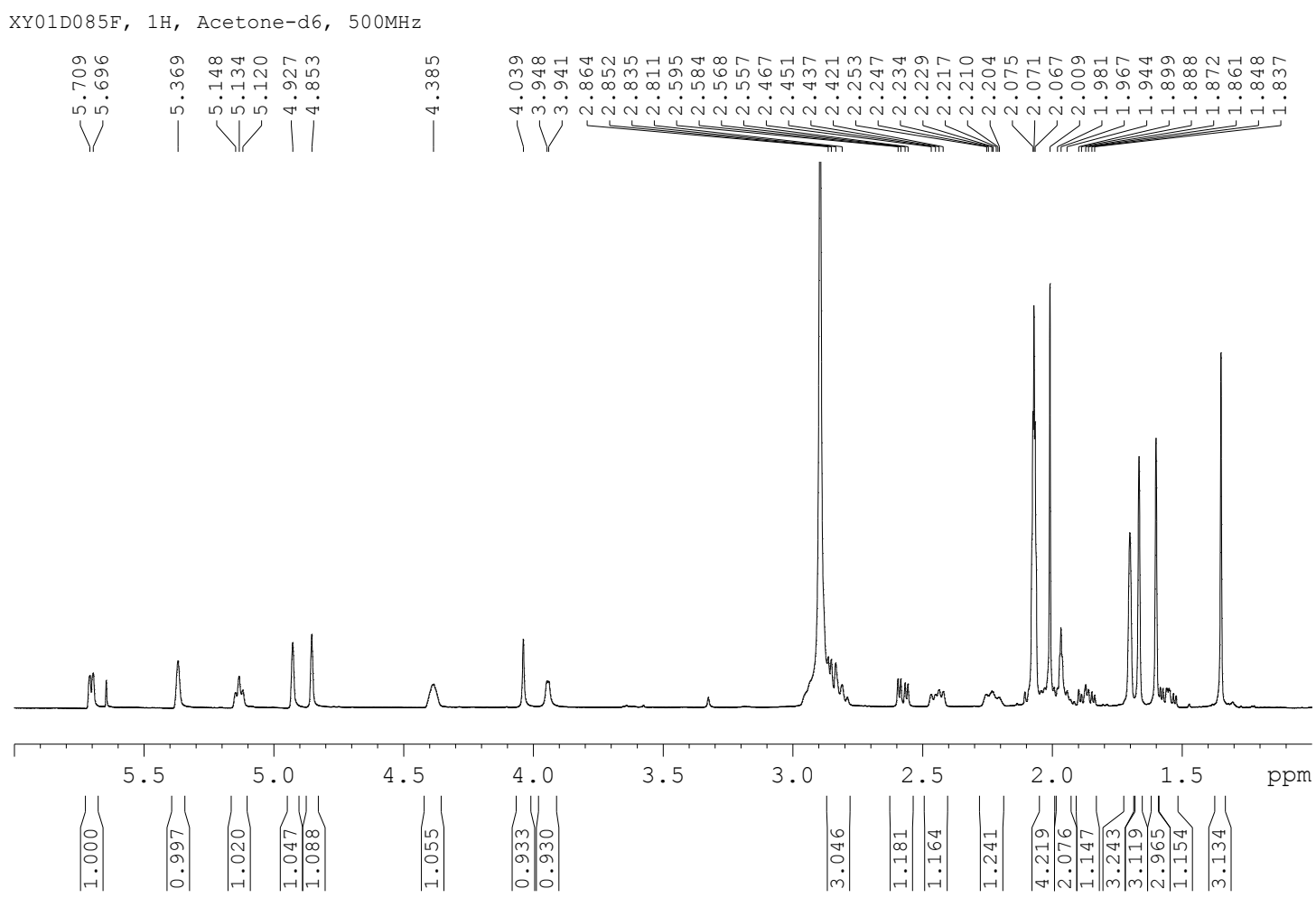


Figure S23. ${ }^{13} \mathrm{C}$ NMR spectrum $(125 \mathrm{MHz})$ of compound 4 in acetone- $d_{6}$.
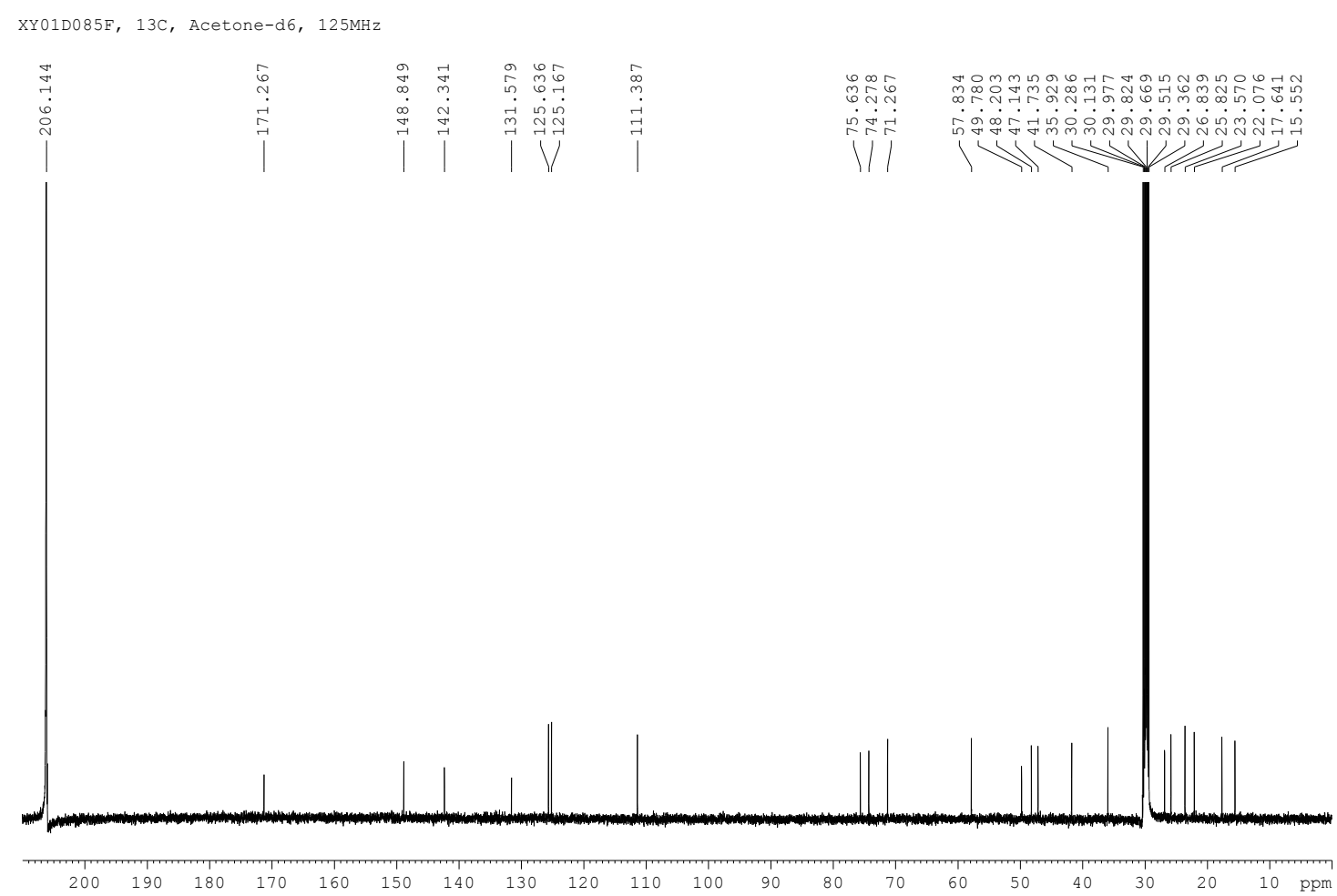

Figure S24. HMQC spectrum of compound 4 in acetone- $d_{6}$.

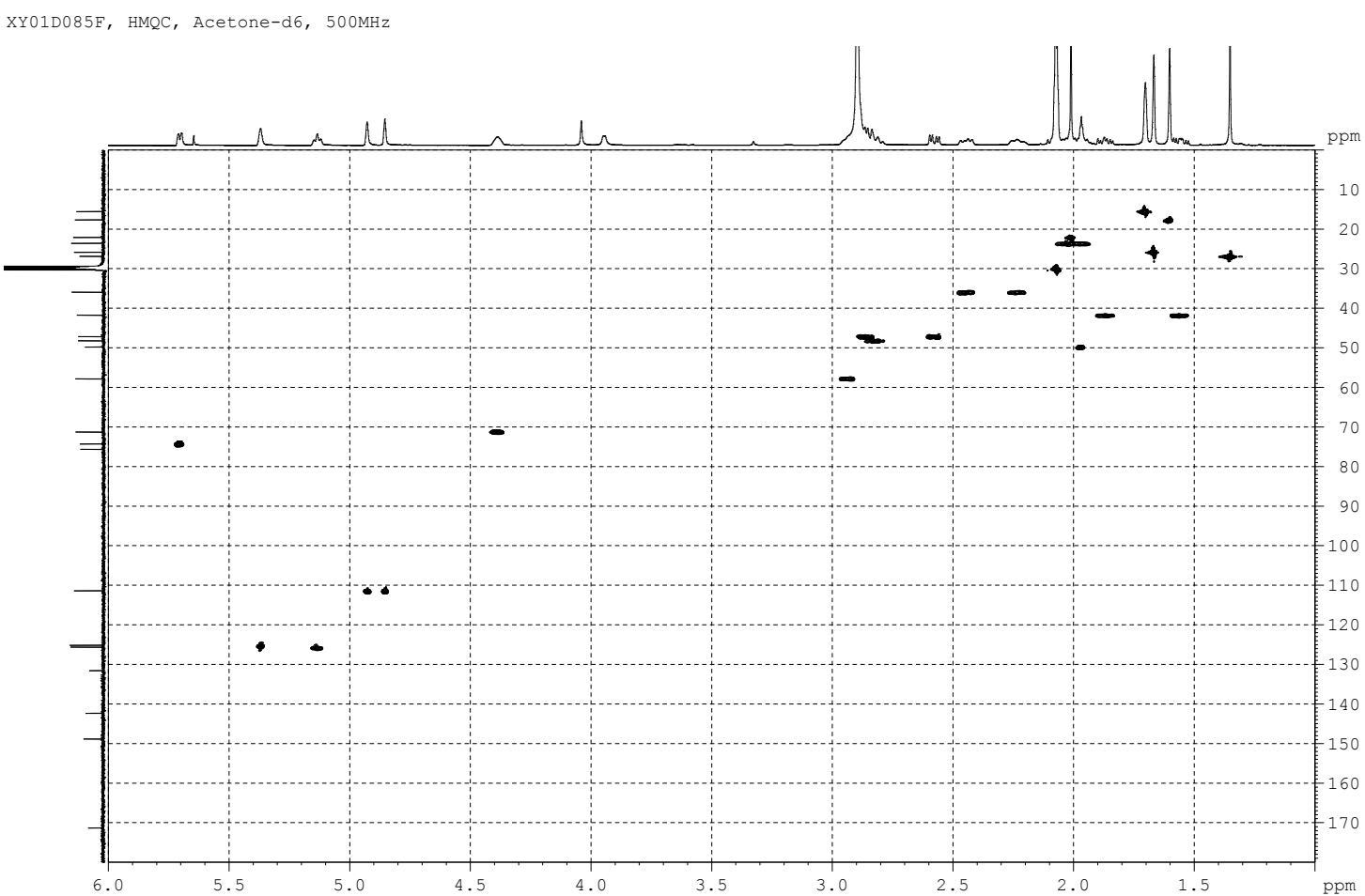


Figure S25. HMBC spectrum of compound 4 in acetone- $d_{6}$.

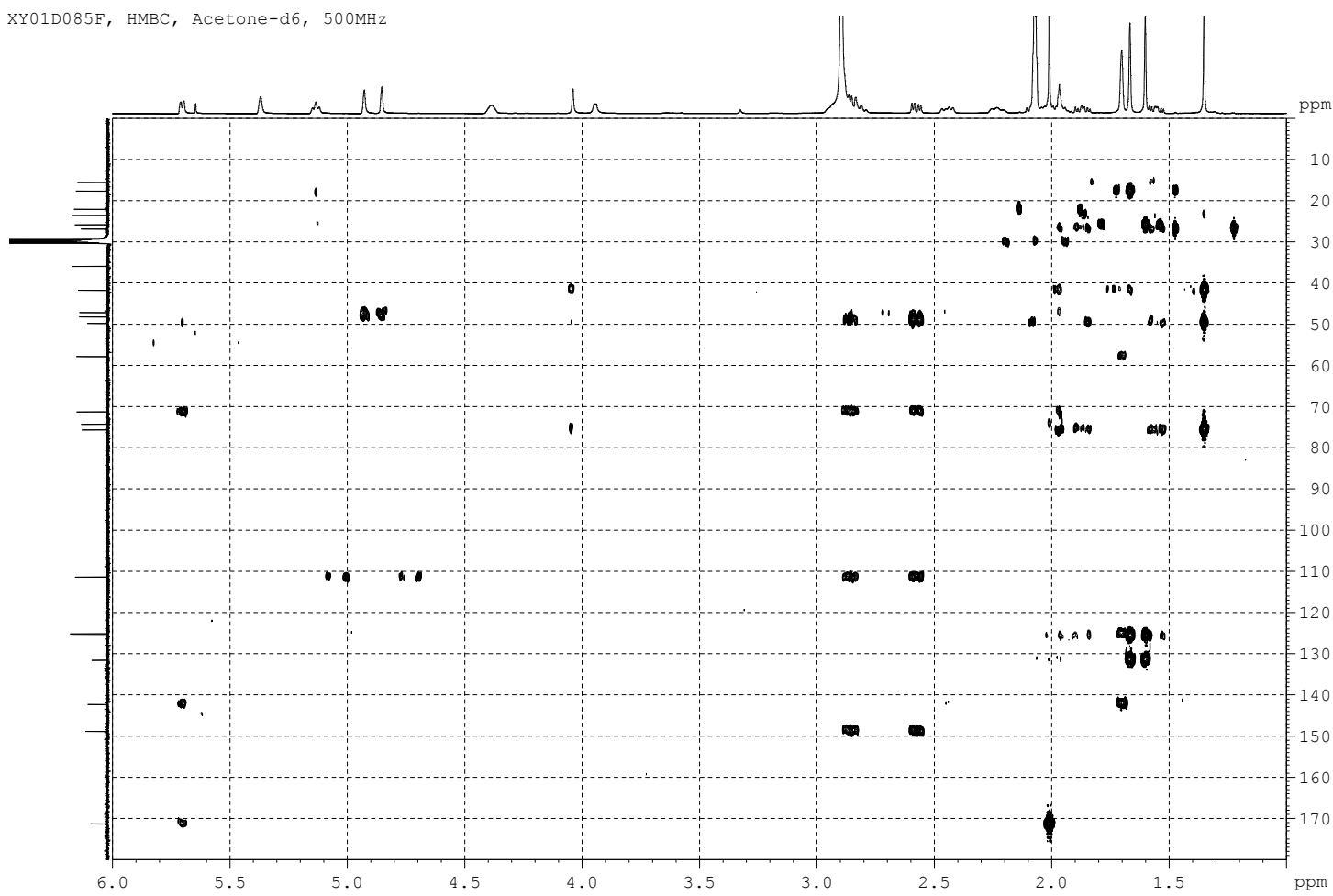

Figure S26. COSY spectrum of compound 4 in acetone- $d_{6}$.

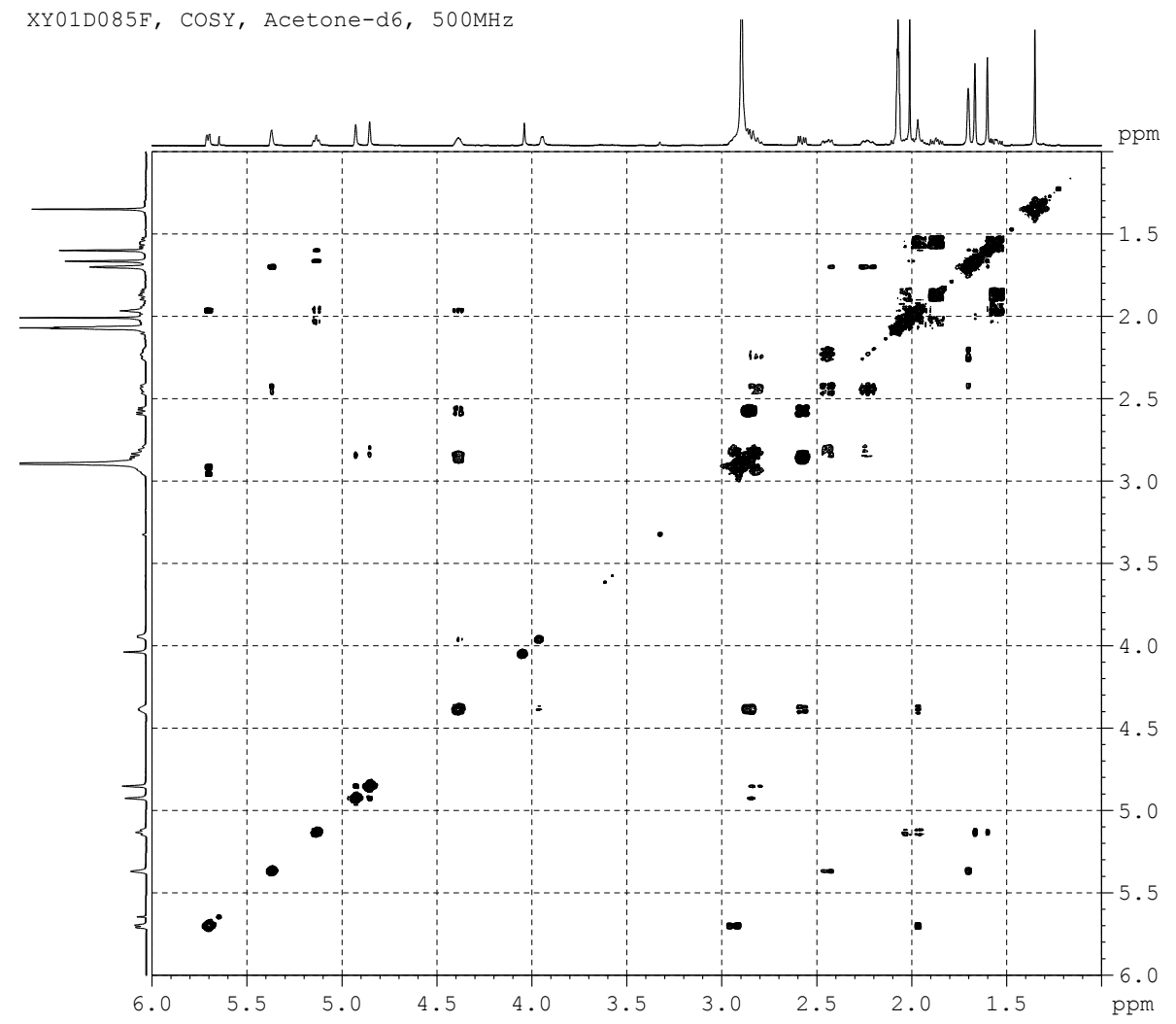


Figure S27. NOESY spectrum of compound 4 in acetone- $d_{6}$.

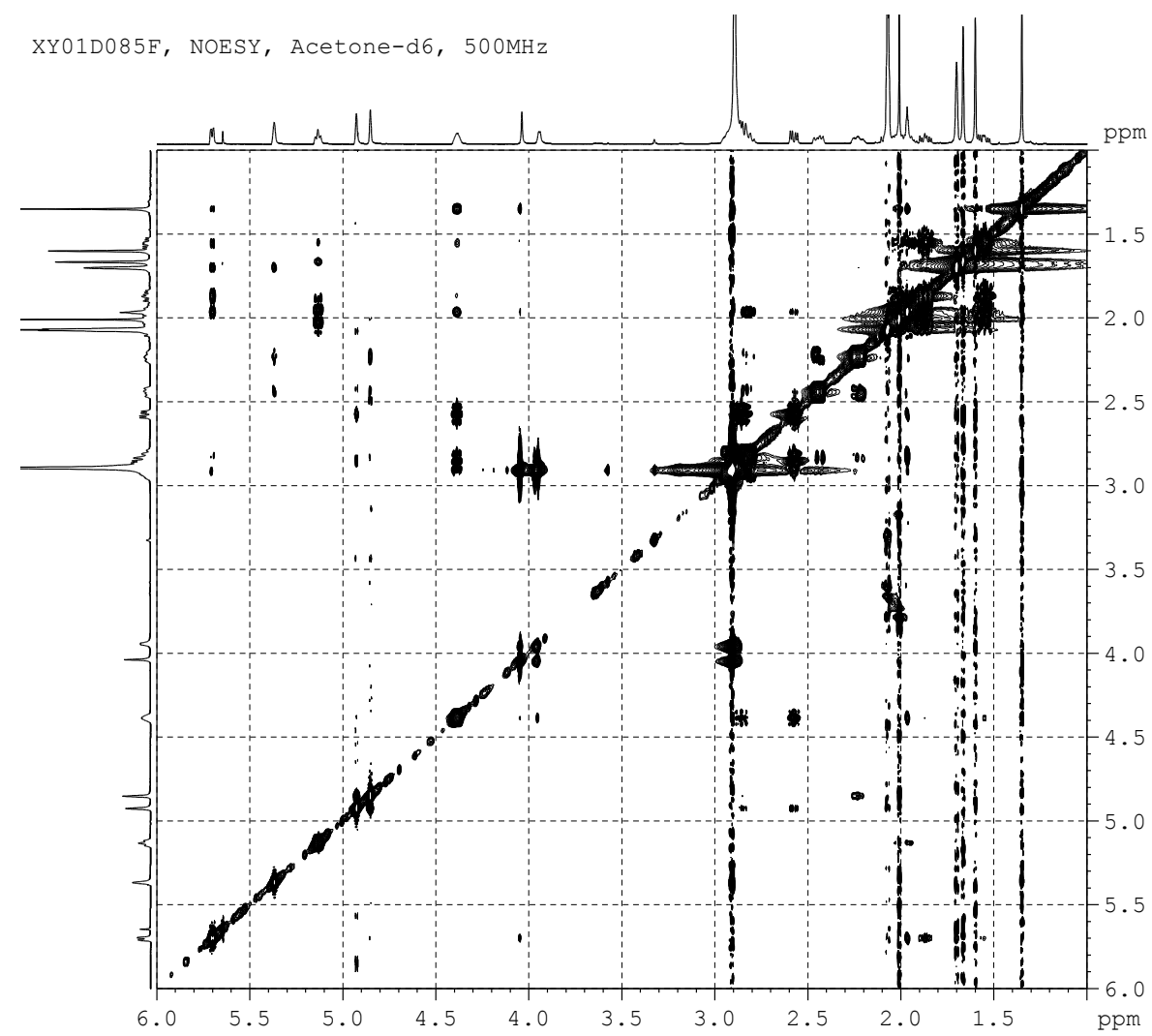

Figure S28. HRESIMS spectrum of compound 4.

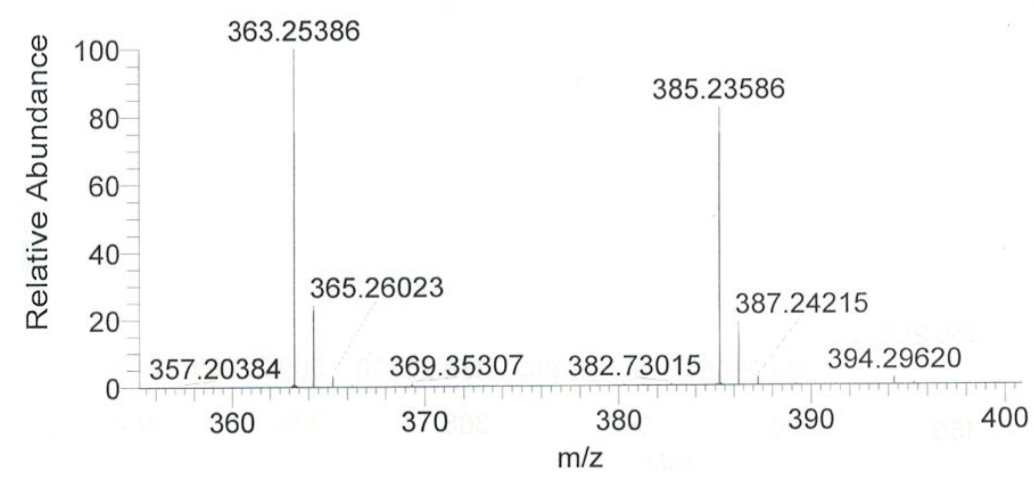

$\mathrm{NL}: 1.02 \mathrm{E} 6$

38-22\#3446 RT: 11.65

AV: 1 SB: 168

11.35-11.91 T: FTMS

$\{1,1\}+p$ ESI Full ms

[200.00-750.00] 
Figure S29. ${ }^{1} \mathrm{H}$ NMR spectrum $(500 \mathrm{MHz})$ of compound 5 in acetone- $d_{6}$.

XY01D080D, 1H, Acetone-d6, 500MHz

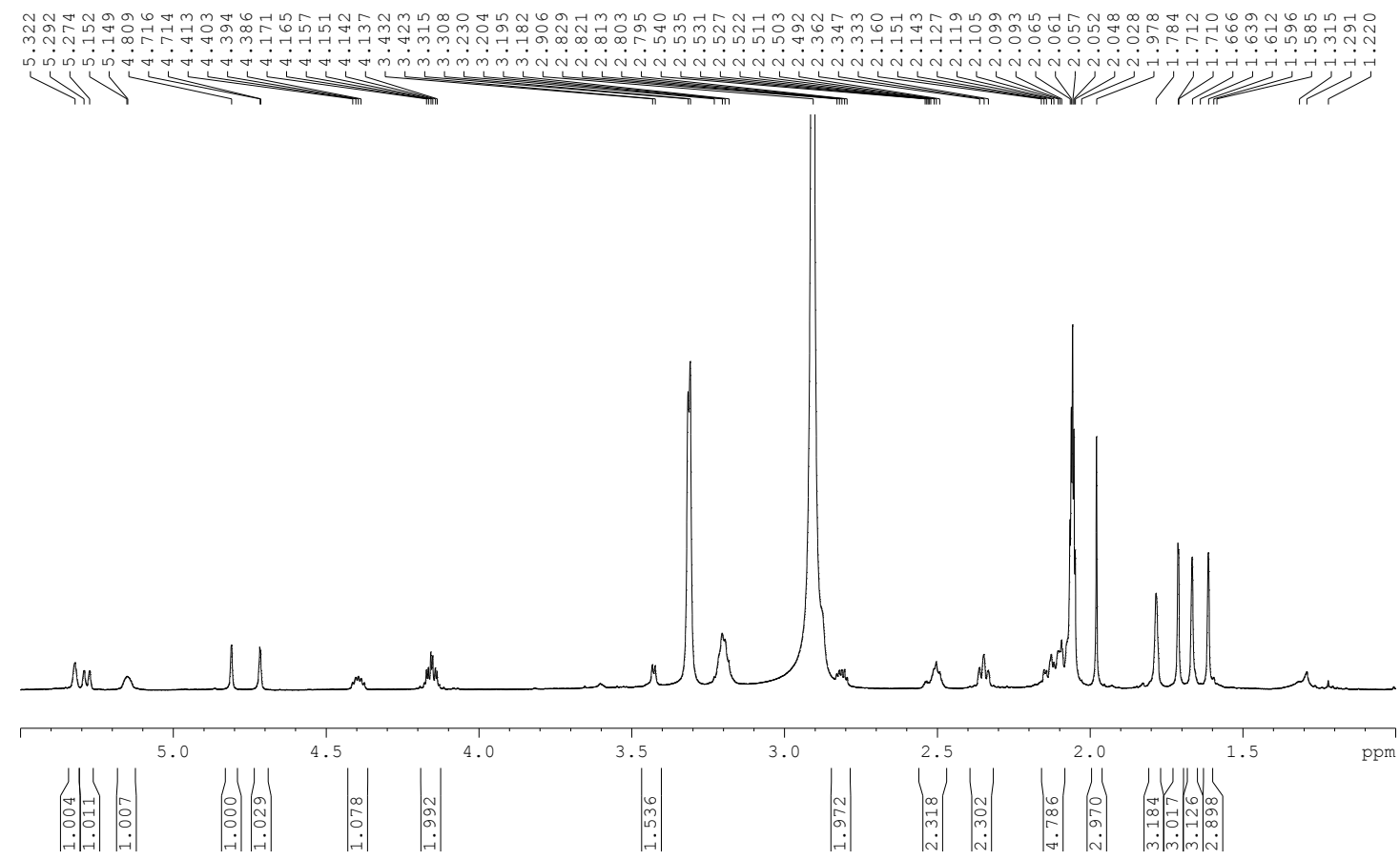

Figure S30. ${ }^{13} \mathrm{C}$ NMR spectrum $(125 \mathrm{MHz})$ of compound 5 in acetone- $d_{6}$.

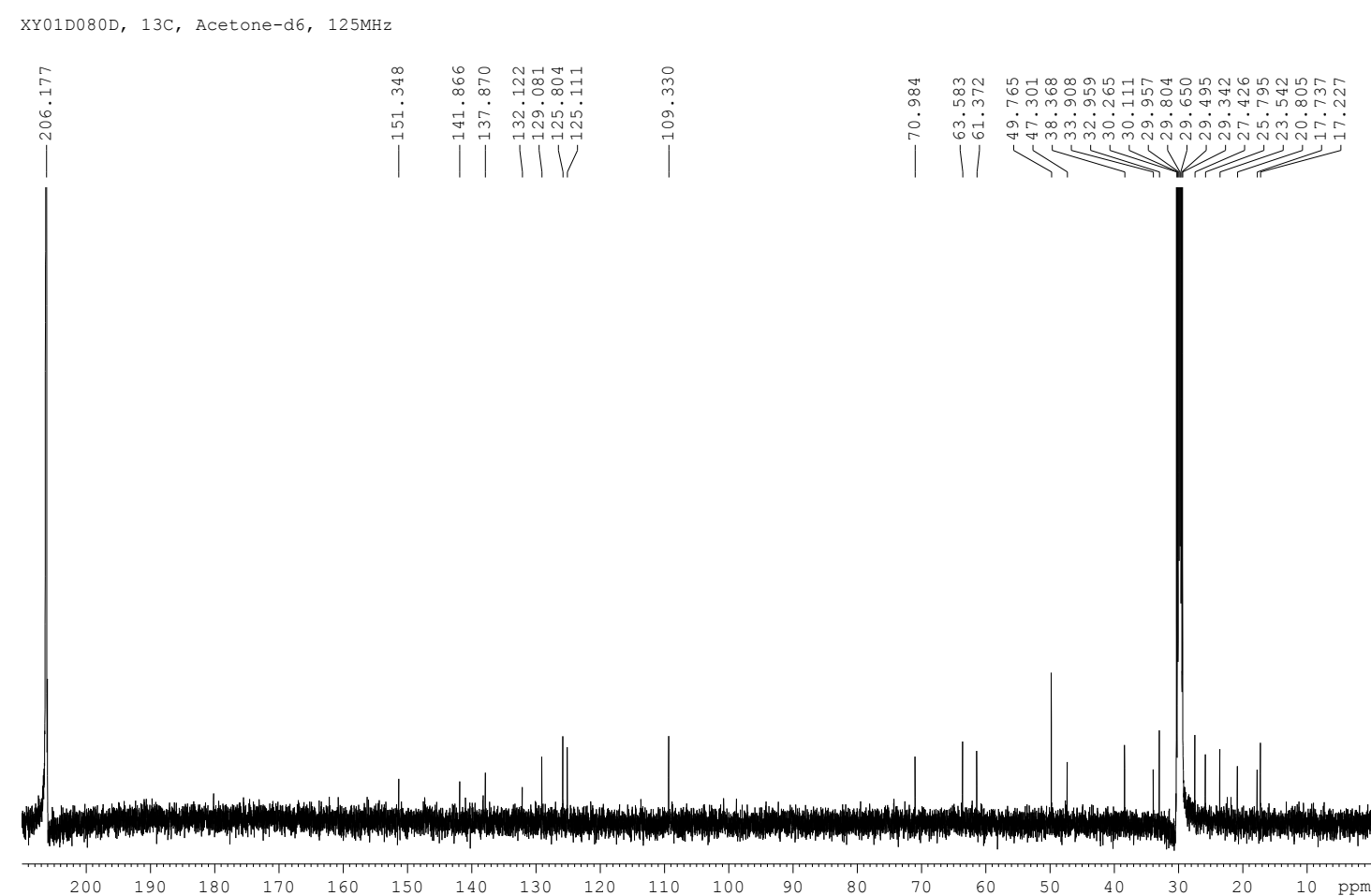


Figure S31. HMQC spectrum of compound 5 in acetone- $d_{6}$.

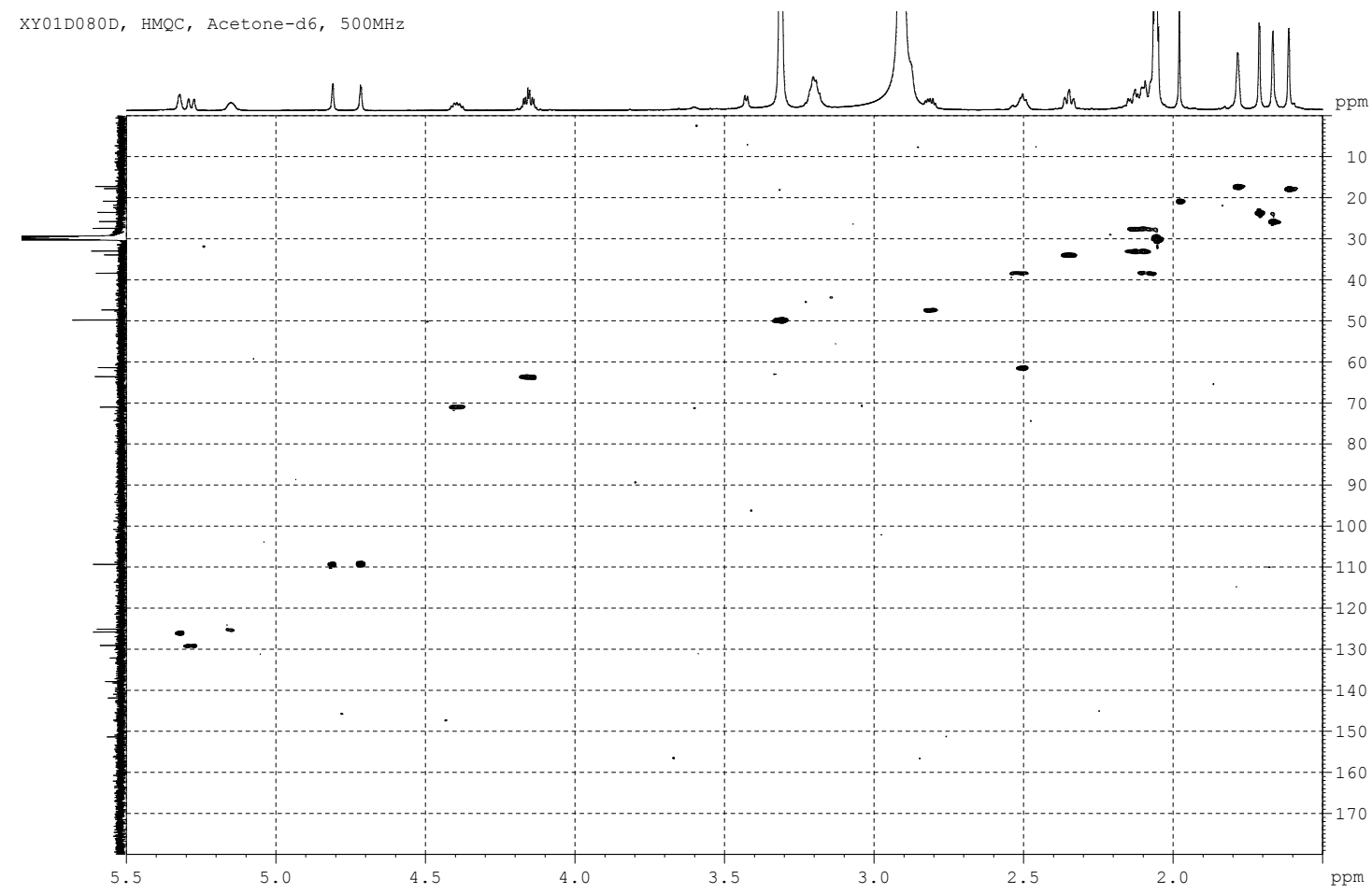

Figure S32. HMBC spectrum of compound 5 in acetone- $d_{6}$.

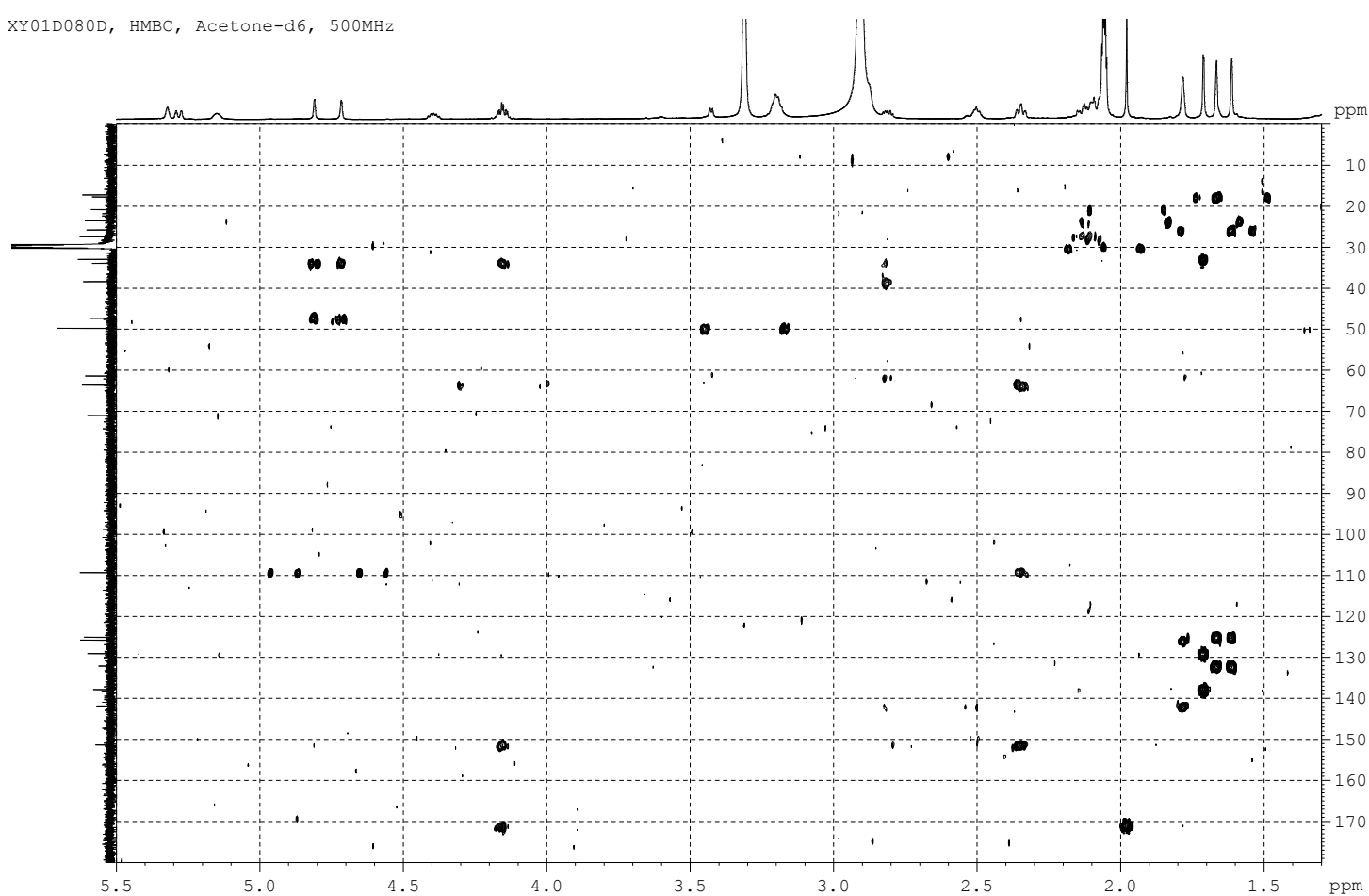


Figure S33. COSY spectrum of compound 5 in acetone- $d_{6}$.

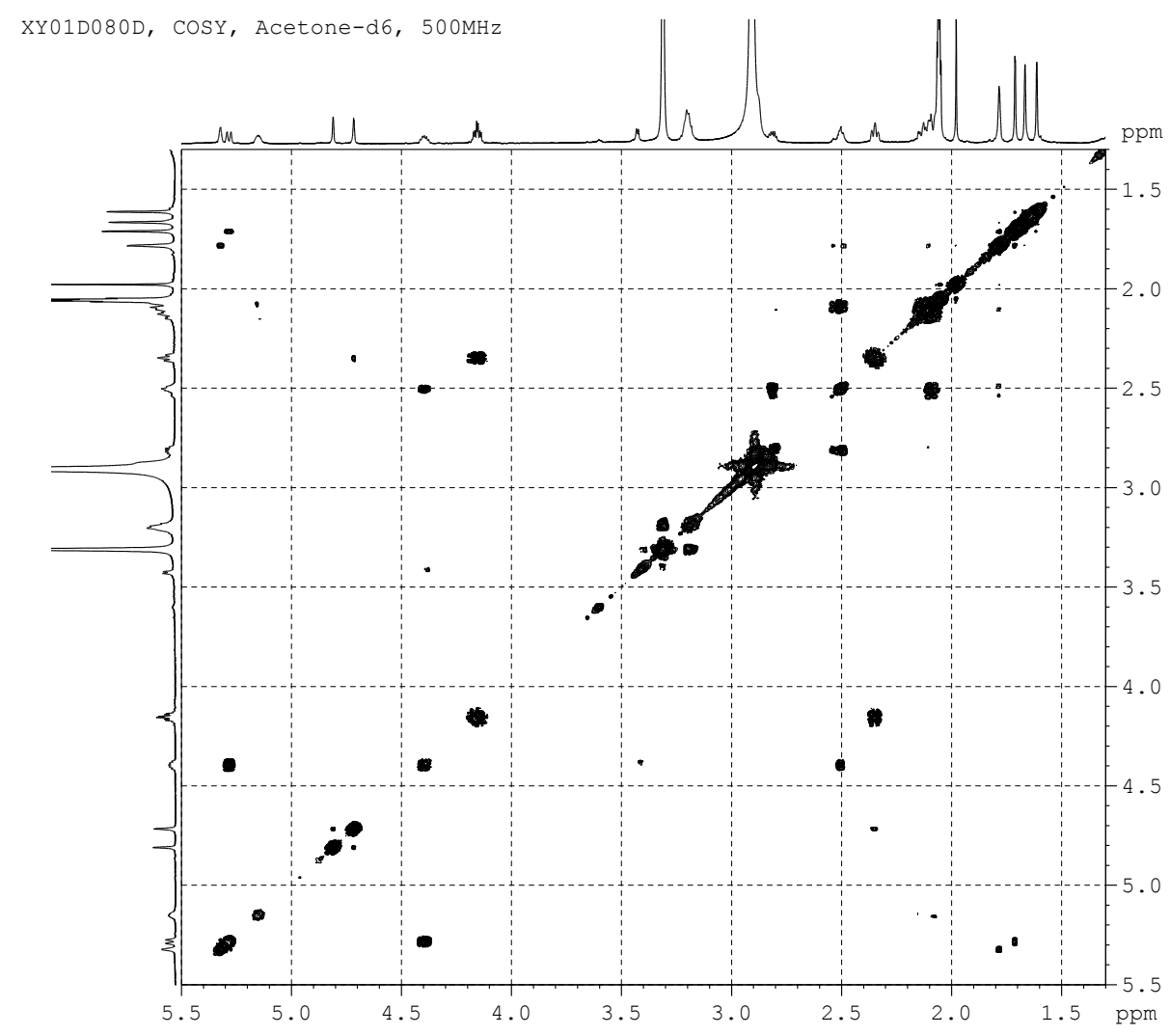

Figure S34. NOESY spectrum of compound 5 in acetone- $d_{6}$.

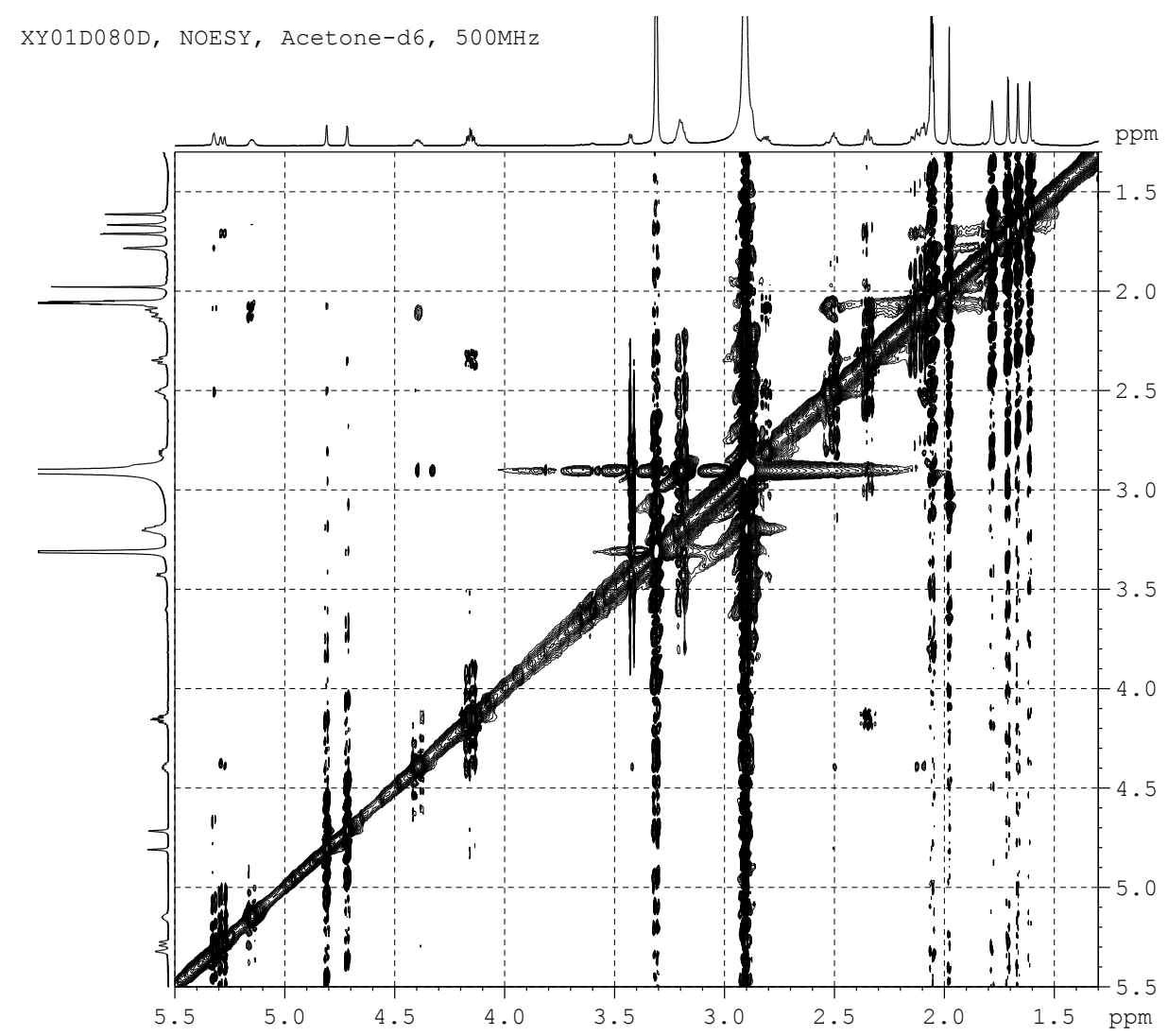


Figure S35. HRESIMS spectrum of compound 5.

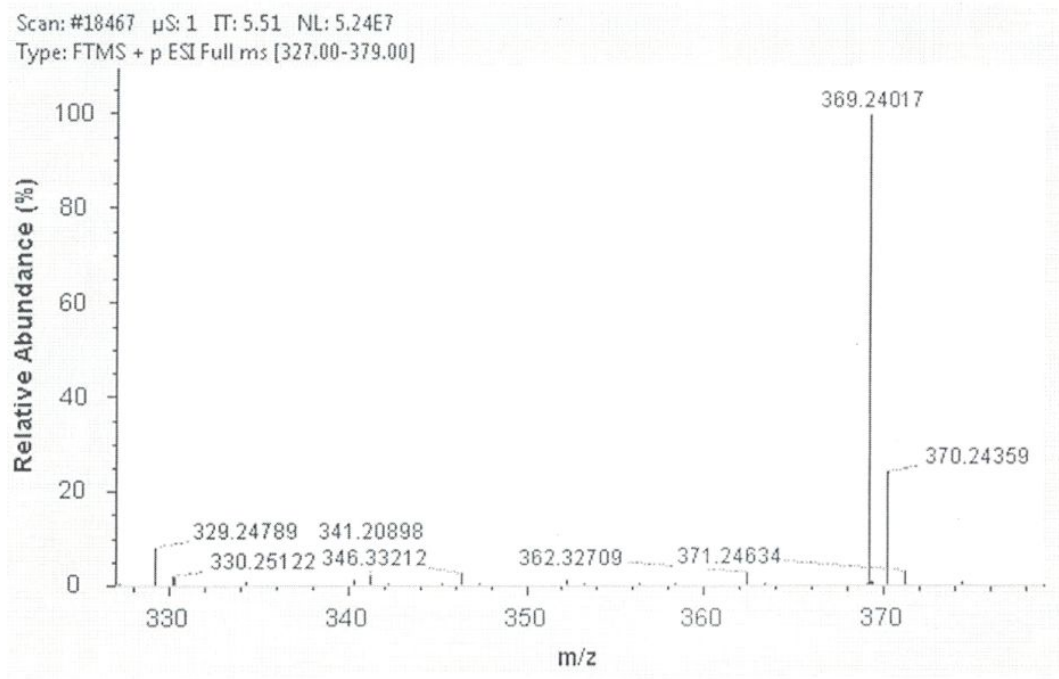

Figure S36. CD spectrum for $\mathrm{Rh}_{2}\left(\mathrm{OCOCF}_{3}\right)_{4}$ complex of compound 1.

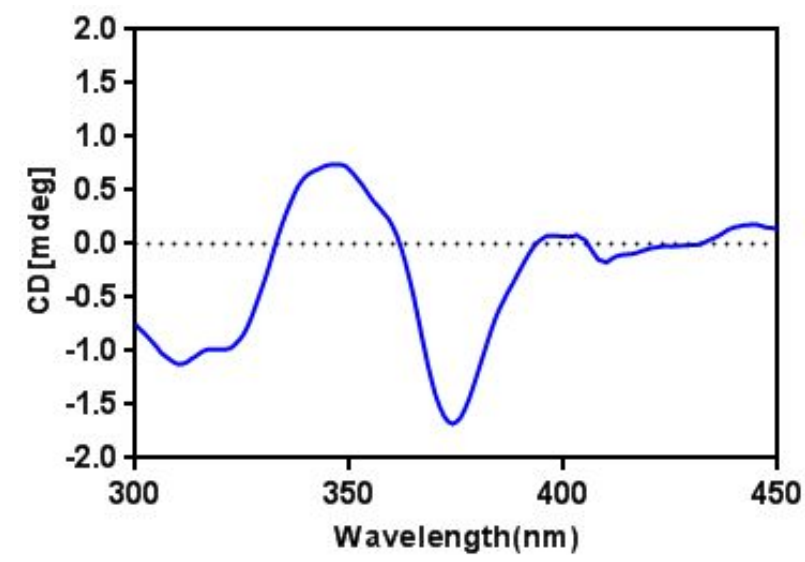


Figure S37. ${ }^{1} \mathrm{H}$ NMR spectrum $(500 \mathrm{MHz})$ of compound 6 in acetone- $d_{6}$.

XY01D85E, 1H, Acetone-d6, 500MHz
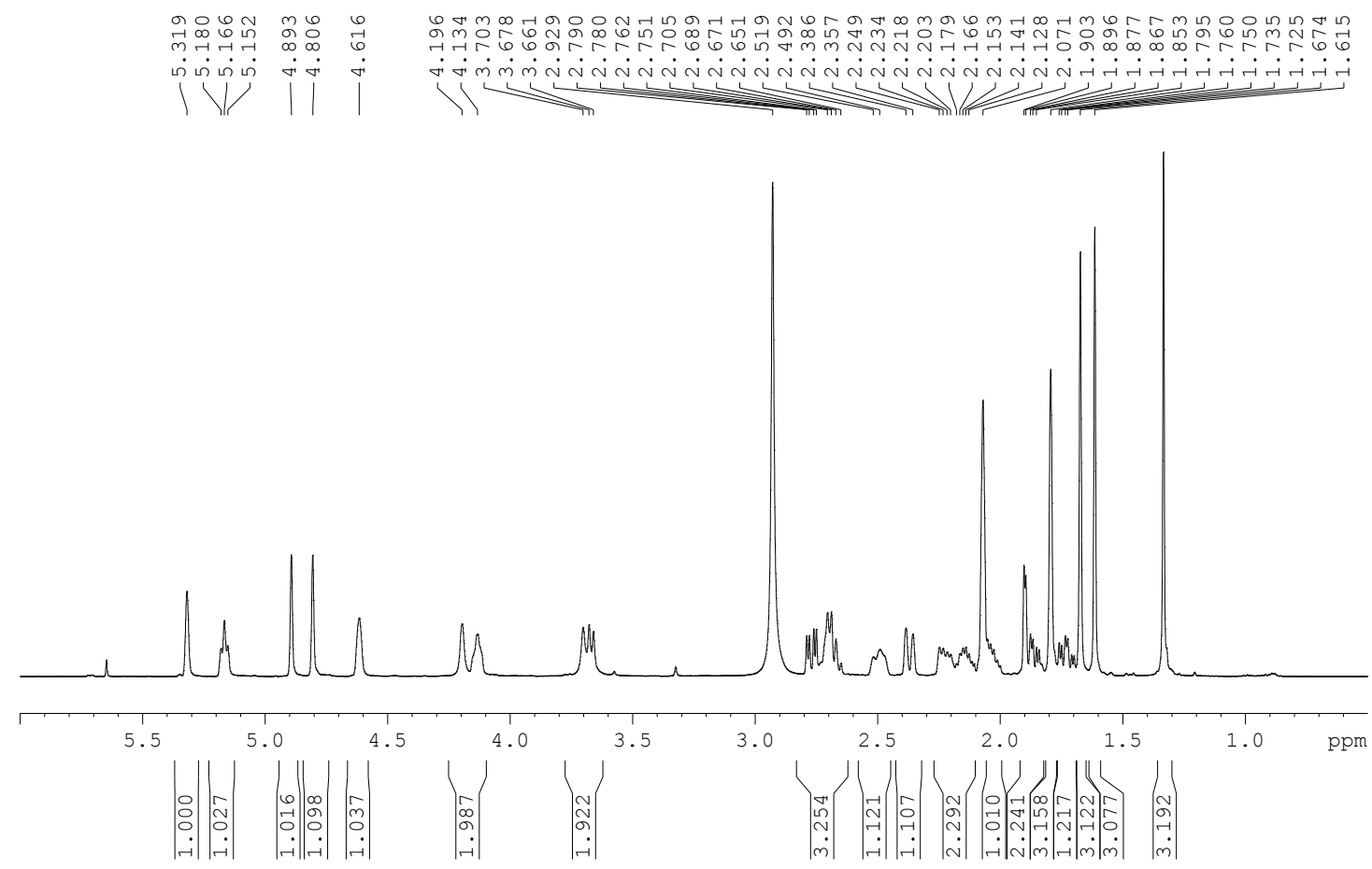

Figure S38. ${ }^{13} \mathrm{C}$ NMR spectrum $(125 \mathrm{MHz})$ of compound 6 in acetone- $d_{6}$. XY01D85E, 13C, Acetone-d6, 125MHz

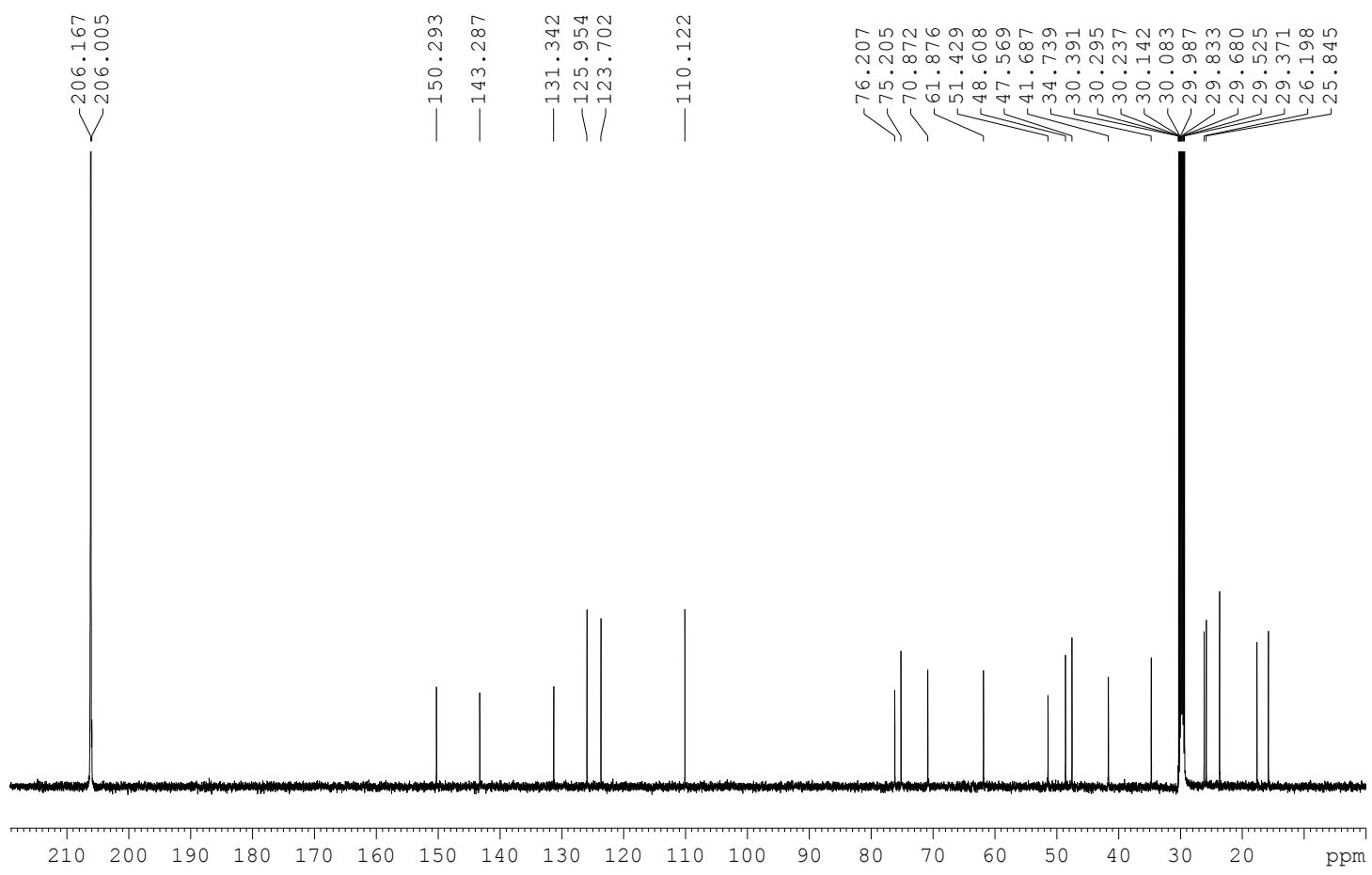


Figure S39. ${ }^{1} \mathrm{H}$ NMR spectrum $(600 \mathrm{MHz})$ of compound 7 in $\mathrm{CDCl}_{3}$.

XY01D82B, 1H, CDC13, 600MHz

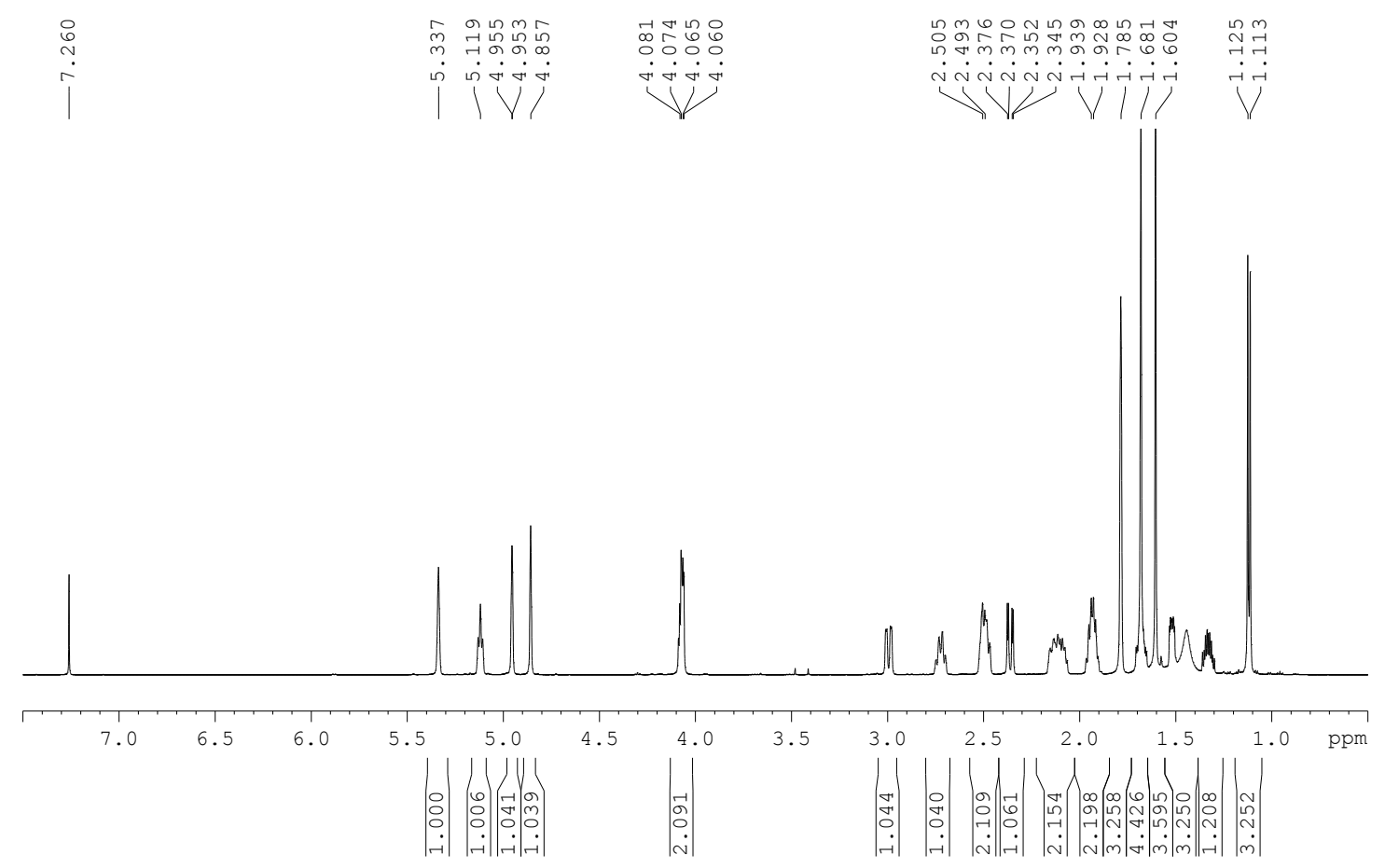

Figure S40. ${ }^{13} \mathrm{C}$ NMR spectrum $(150 \mathrm{MHz})$ of compound 7 in $\mathrm{CDCl}_{3}$.

XY01D82B, 13C, CDC13, 150MHz
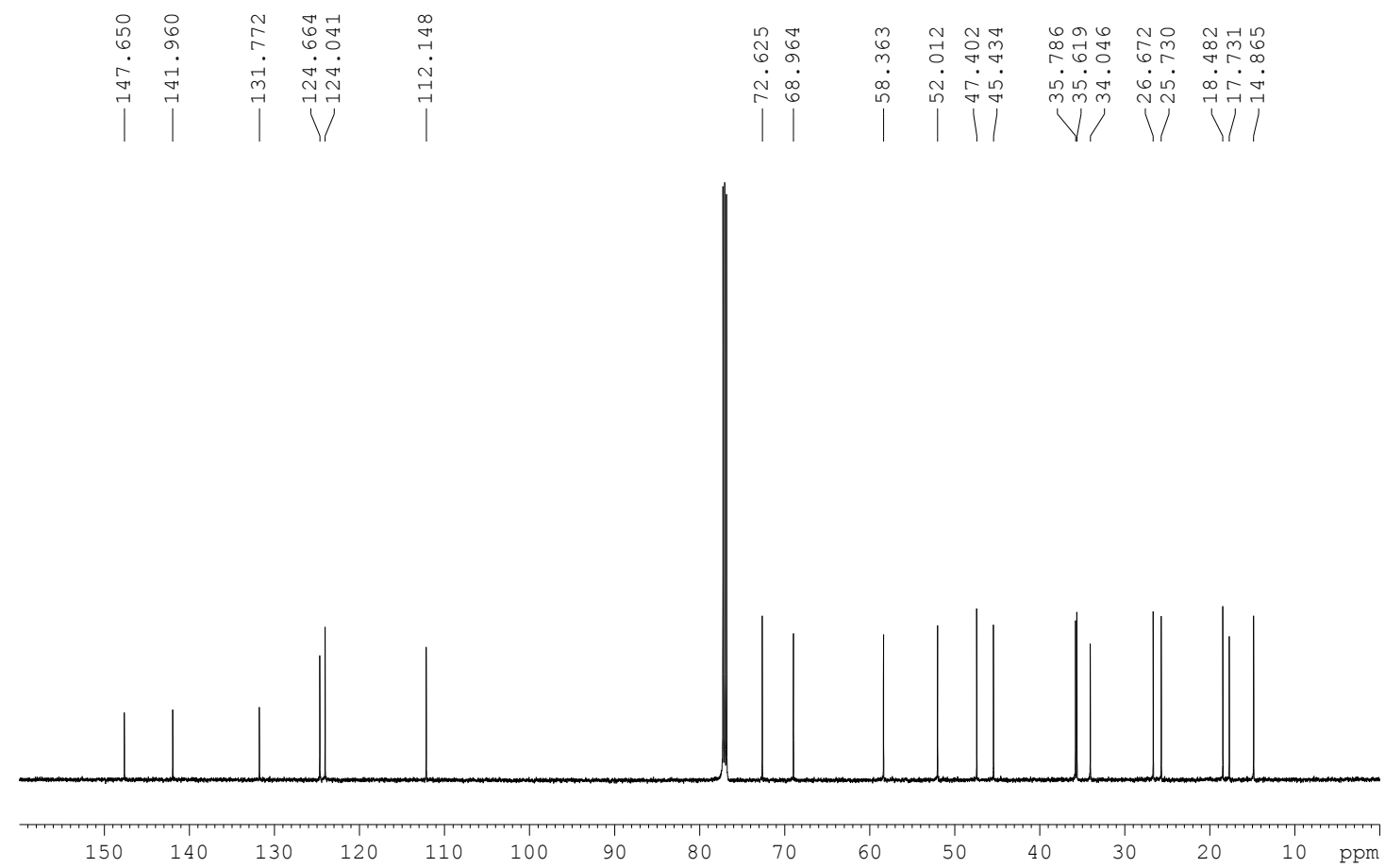
Figure $\mathbf{S 4 1} .{ }^{1} \mathrm{H}$ NMR spectrum $(600 \mathrm{MHz})$ of compound 8 in acetone- $d_{6}$.

XY01B69B, 1H, Acetone-d6, 600MHz

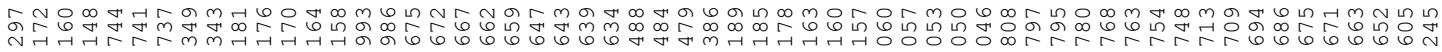

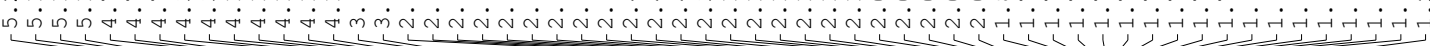

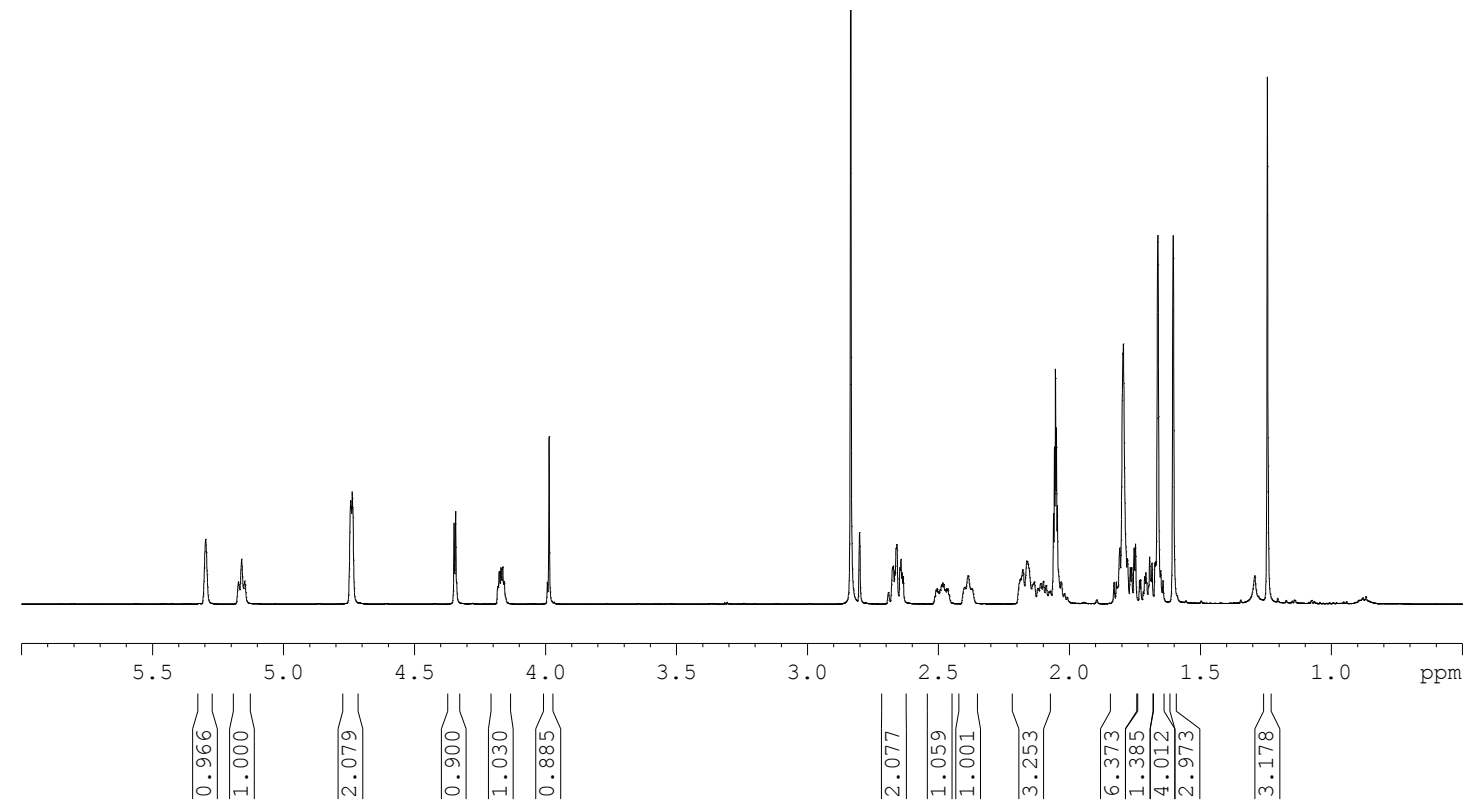

Figure S42. ${ }^{13} \mathrm{C}$ NMR spectrum $(150 \mathrm{MHz})$ of compound 8 in acetone- $d_{6}$. XY01B69B, 13C, Acetone-d6, 150MHz

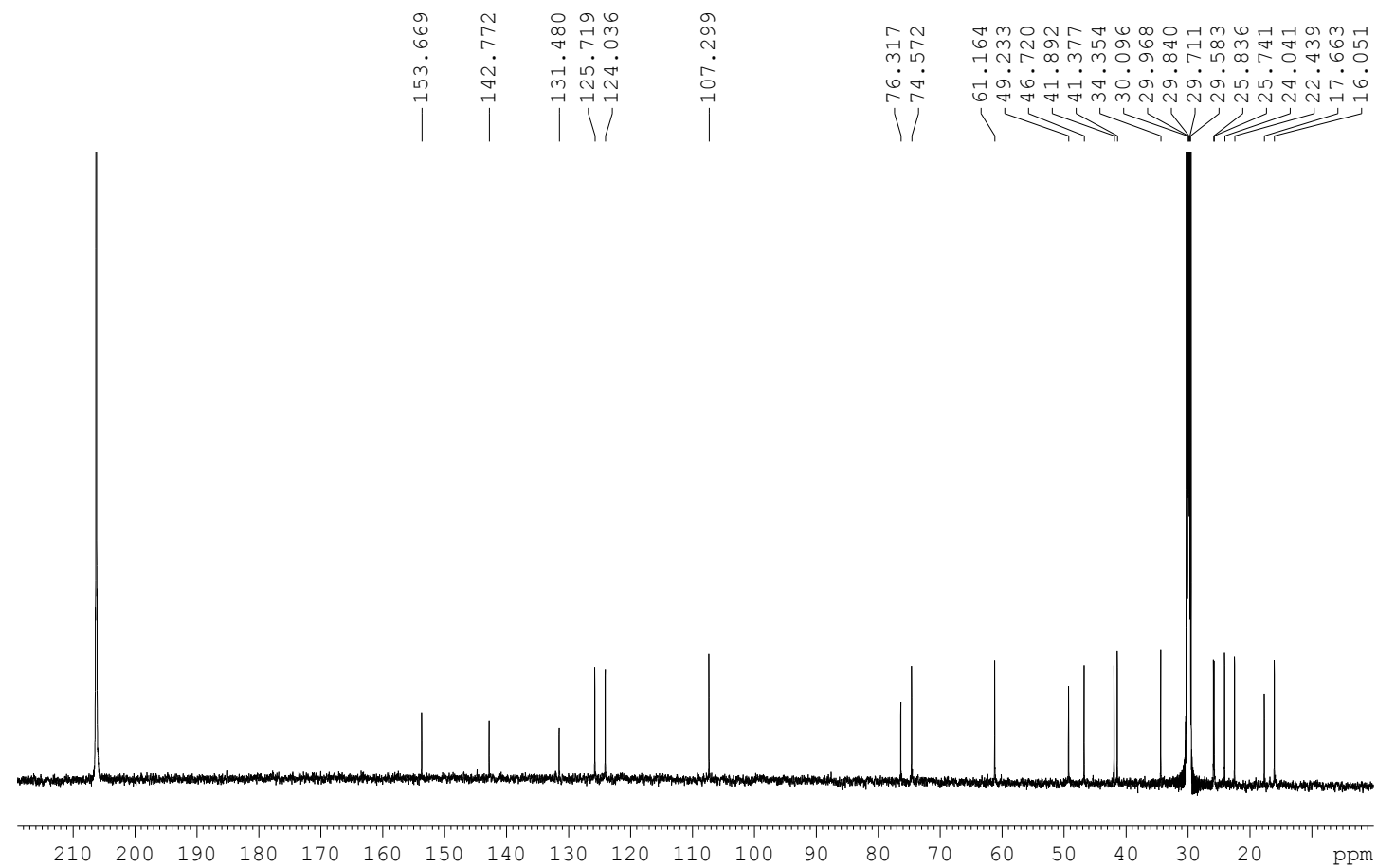


Figure $\mathbf{S 4 3} .{ }^{1} \mathrm{H}$ NMR spectrum $(600 \mathrm{MHz})$ of compound 9 in acetone- $d_{6}$.

XY01B59C, 1H, Acetone-d6, 600MHz

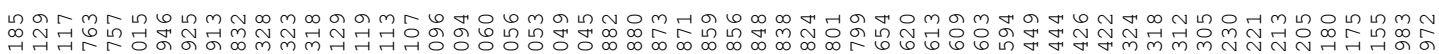

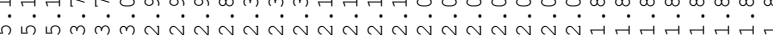

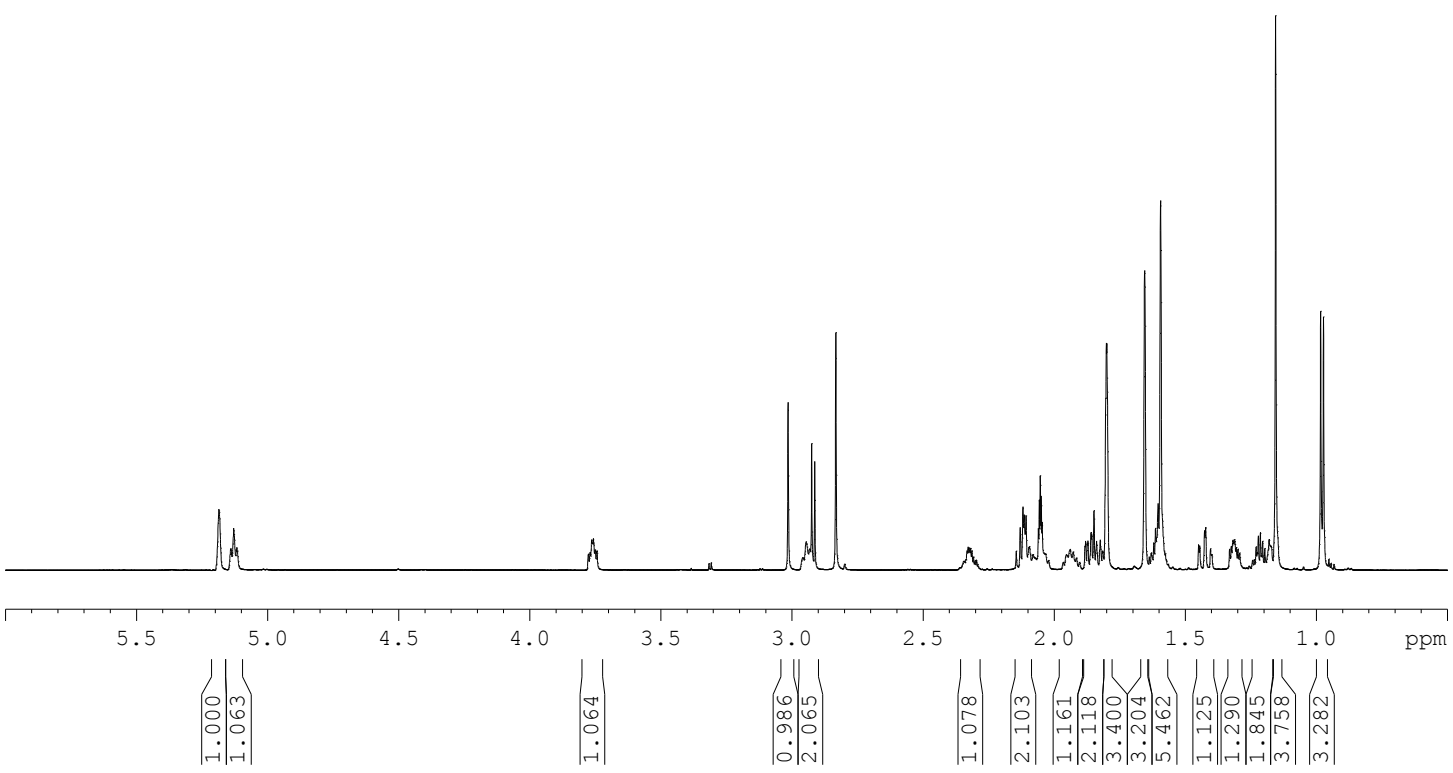

Figure S44. ${ }^{13} \mathrm{C}$ NMR spectrum $(150 \mathrm{MHz})$ of compound 9 in acetone- $d_{6}$.

XY01B59C, 13C, Acetone-d6, 150MHz

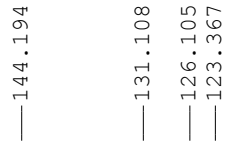
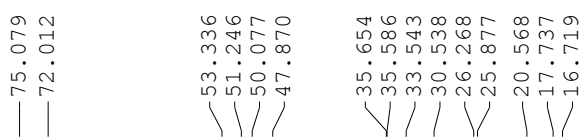

inं

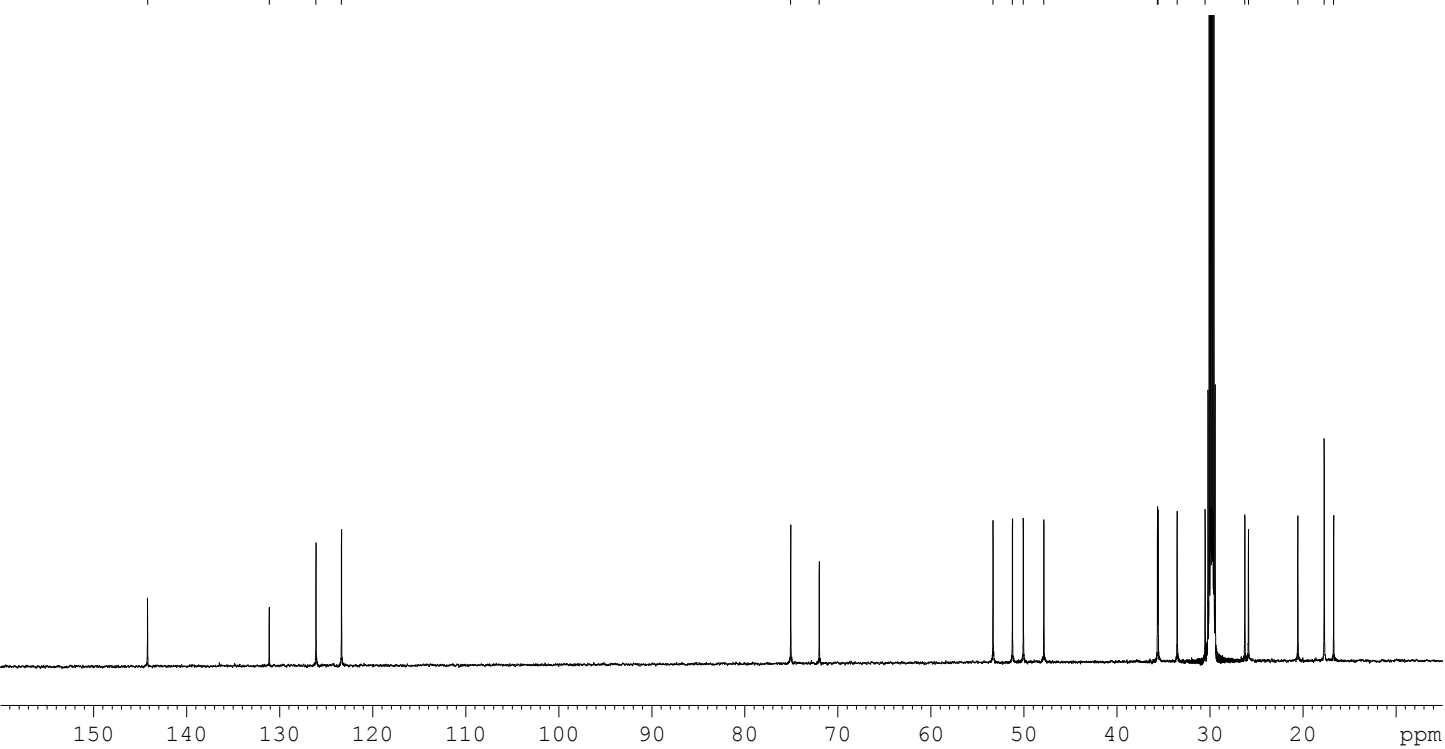


Figure S45. ${ }^{1} \mathrm{H}$ NMR spectrum $(600 \mathrm{MHz})$ of compound 10 in acetone- $d_{6}$.

XY01B67B, 1H, Acetone-d6, 600MHz

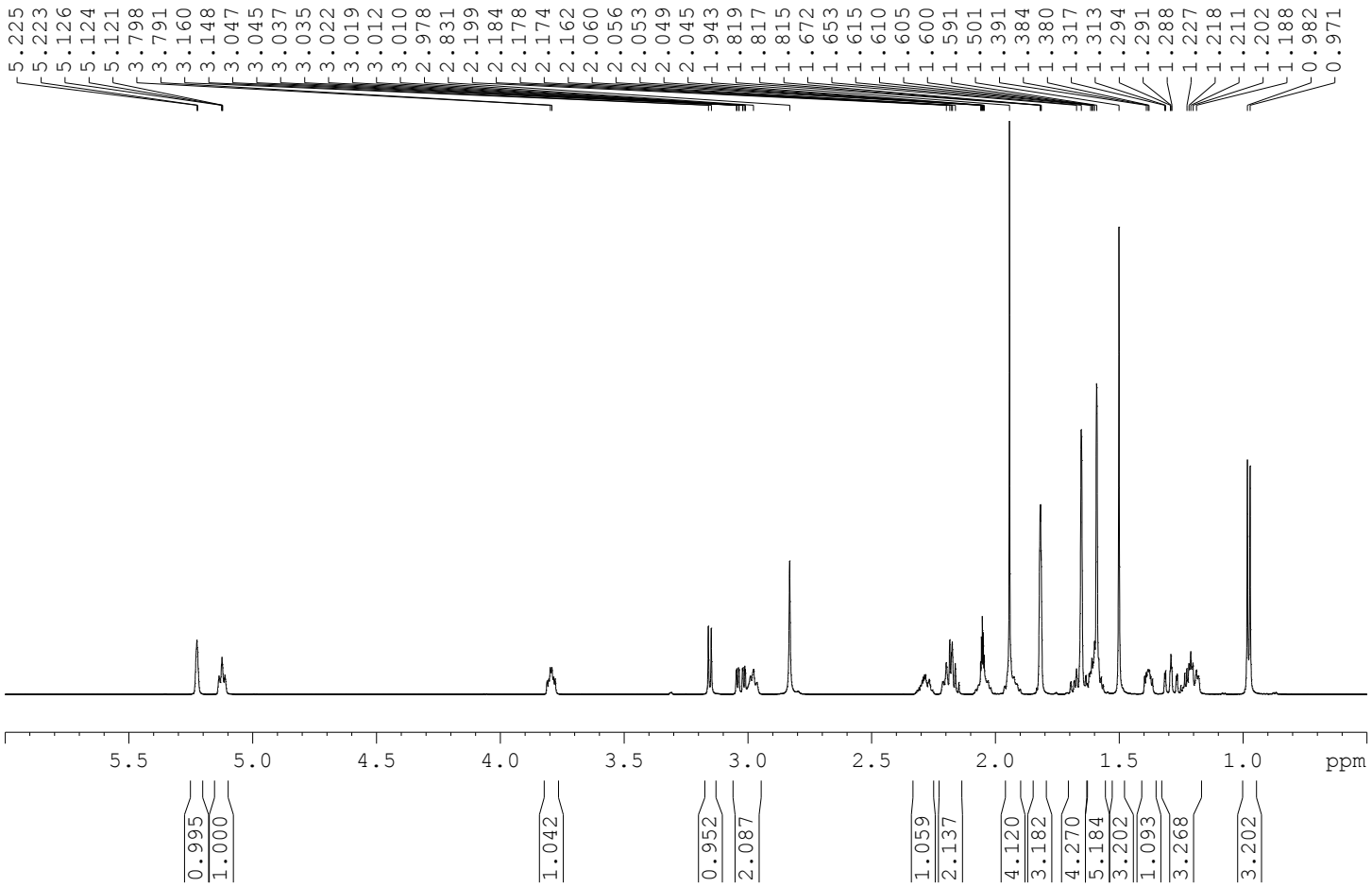

Figure S46. ${ }^{13} \mathrm{C}$ NMR spectrum $(150 \mathrm{MHz})$ of compound 10 in acetone- $d_{6}$. XY01B67B, 13C, Acetone-d6, 150MHz

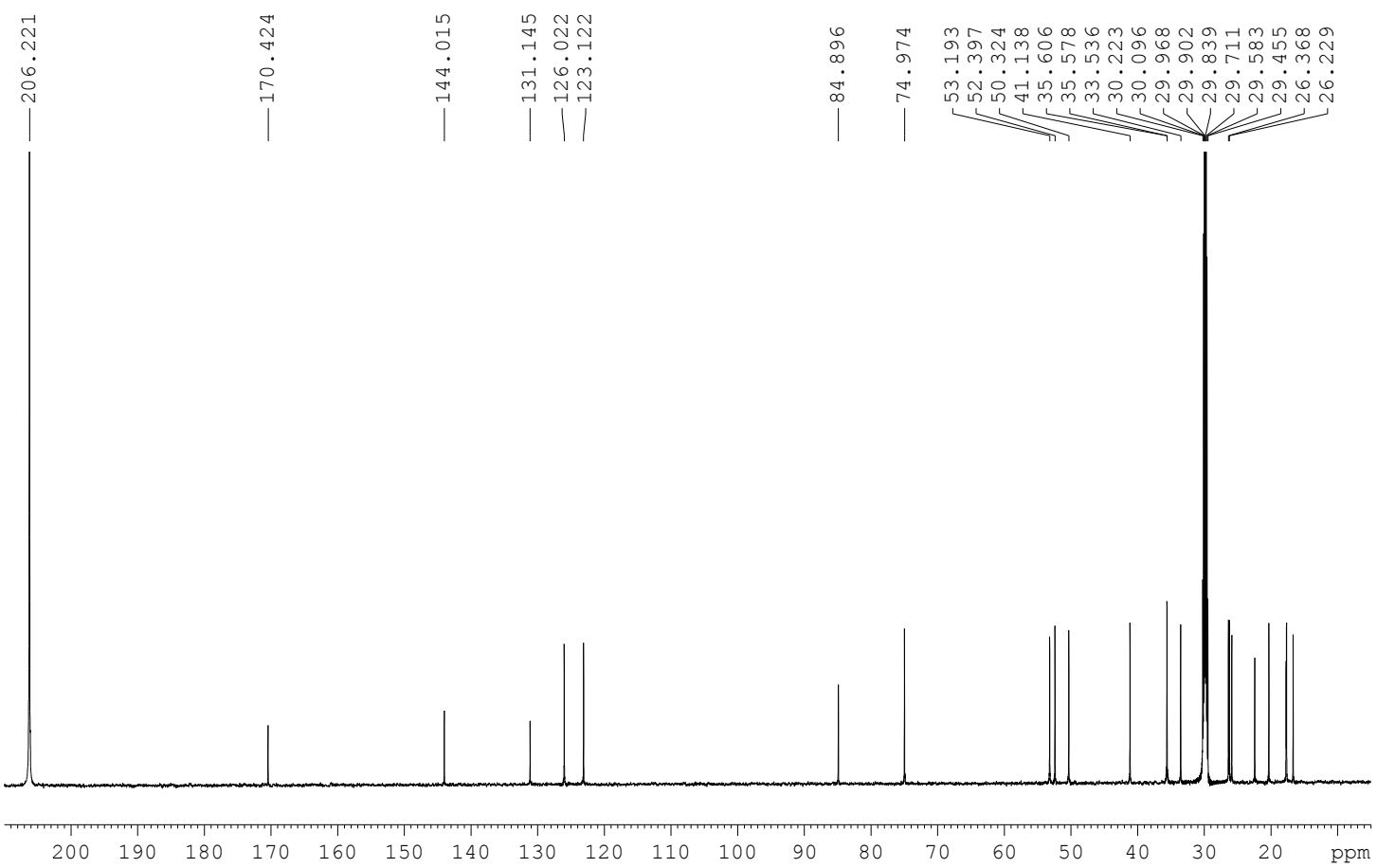


Figure S47. The cytoprotection of EtOAc extract of Dictyota sp. nov. on PC12 cells in the $\mathrm{H}_{2} \mathrm{O}_{2}$ damage model.

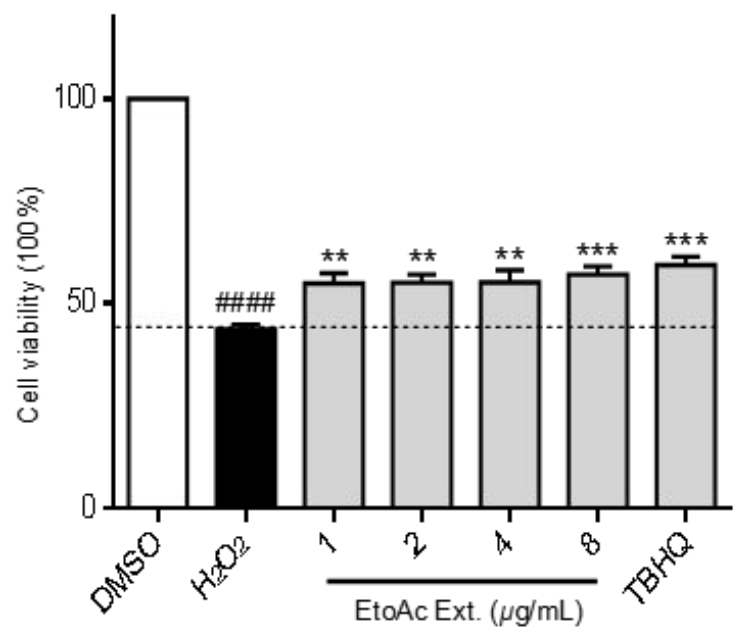

PC12 cells were pretreated with different concentrations of EtOAc extract of Dictyota sp. nov. for $24 \mathrm{~h}$, and then treated with $450 \mu \mathrm{M}$ of $\mathrm{H}_{2} \mathrm{O}_{2}$ for $24 \mathrm{~h}$. The cell viability was determined by the MTT assay and the viability of untreated cells is defined as $100 \%$. TBHQ ( $5 \mu \mathrm{M})$ was used as a positive control. Data are expressed as the mean $\pm \mathrm{SD}, \mathrm{n}=3$. ${ }^{\# \# \#} \mathrm{P}<0.0001$ vs DMSO; ${ }^{* * *} \mathrm{P}<$ $0.001,{ }^{* *} \mathrm{P}<0.01$ vs $\mathrm{H}_{2} \mathrm{O}_{2}$. 
Table S1. ${ }^{1}$ H NMR Data for compounds 6-10 ${ }^{a}$

\begin{tabular}{|c|c|c|c|c|c|}
\hline no. & $\mathbf{6}^{b}$ & $7^{c}$ & $\mathbf{8}^{c}$ & $\mathbf{9}^{c}$ & $10^{c}$ \\
\hline 1 & $2.68, \mathrm{~m}$ & $2.72, \mathrm{dd}(19.8,7.8)$ & $2.66, \mathrm{~m}$ & $2.11, \mathrm{~m}$ & $2.19, \mathrm{~m}$ \\
\hline \multirow[t]{2}{*}{2} & $2.49, \mathrm{~m}$ & $2.49, \mathrm{~m}$ & $2.48, \mathrm{~m}$ & $2.32, \mathrm{~m}$ & $2.29, \mathrm{~m}$ \\
\hline & $2.22, \mathrm{~m}$ & $2.13, \mathrm{~m}$ & $2.17, \mathrm{~m}$ & $2.10, \mathrm{~m}$ & $2.17, \mathrm{~m}$ \\
\hline 3 & 5.32 , br s & 5.34 , br s & 5.30, br s & 5.19 , br s & 5.22 , br s \\
\hline 5 & $2.71, \mathrm{~m}$ & $2.50, \mathrm{~m}$ & $2.39, \mathrm{t}(8.4)$ & $2.94, \mathrm{~m}$ & $2.98, \mathrm{t}(8.4)$ \\
\hline 6 & $4.13, \mathrm{t}(5.5)$ & $4.07, \mathrm{~m}$ & $4.17, \mathrm{~m}$ & $3.76, \mathrm{~m}$ & $3.79, \mathrm{~m}$ \\
\hline \multirow[t]{2}{*}{7} & $1.90, \mathrm{~d}(3.5)$ & $1.52, \mathrm{ddd}$ & $1.75, \mathrm{~m}$ & $1.31, \mathrm{~m}$ & $1.38, \mathrm{ddd}$ \\
\hline & & $(6.6,4.2,2.4)$ & & & $(8.4,6.6,4.2)$ \\
\hline \multirow[t]{2}{*}{8} & $4.62, \mathrm{br} \mathrm{s}$ & $4.08, \mathrm{~m}$ & $1.80, \mathrm{~m}$ & $1.86, \mathrm{~m}$ & $1.67, \mathrm{~m}$ \\
\hline & & & $1.69, \mathrm{~m}$ & $1.18, \mathrm{~m}$ & $1.20, \mathrm{~m}$ \\
\hline \multirow[t]{4}{*}{9} & $2.77, \mathrm{dd}(14.0,4.5)$ & $2.99, \mathrm{dd}(14.4,3.0)$ & $2.65, \mathrm{~m}$ & $1.87, \mathrm{~m}$ & 3.03, ddd \\
\hline & 2.37, br d (14.0) & 2.36, dd $(14.4,3.6)$ & $2.16, \mathrm{~m}$ & $1.42, \operatorname{td}(13.2,2.4)$ & $(15.0,5.4,1.2)$ \\
\hline & & & & & $1.29, \mathrm{ddd}$ \\
\hline & & & & & $(15.0,13.2,2.4)$ \\
\hline 11 & & $1.94, \mathrm{~m}$ & & $1.61, \mathrm{~m}$ & $1.60, \mathrm{~m}$ \\
\hline \multirow[t]{2}{*}{12} & $1.86, \mathrm{dd}(12.0,5.0)$ & $1.68, \mathrm{~m}$ & $1.81, \mathrm{~m}$ & $1.60, \mathrm{~m}$ & $1.62, \mathrm{~m}$ \\
\hline & $1.73, \operatorname{td}(12.5,5.0)$ & $1.33, \mathrm{~m}$ & $1.67, \mathrm{~m}$ & $1.21, \mathrm{~m}$ & $1.22, \mathrm{~m}$ \\
\hline \multirow[t]{2}{*}{13} & $2.14, \mathrm{~m}$ & $2.10, \mathrm{~m}$ & $2.11, \mathrm{~m}$ & $2.06, \mathrm{~m}$ & $2.04, \mathrm{~m}$ \\
\hline & $2.04, \mathrm{~m}$ & $1.92, \mathrm{~m}$ & $2.03, \mathrm{~m}$ & $1.93, \mathrm{~m}$ & $1.93, \mathrm{~m}$ \\
\hline 14 & $5.17, \mathrm{t}(7.0)$ & $5.12, \mathrm{t}(7.2)$ & $5.16, \mathrm{t}(7.2)$ & $5.13, \mathrm{t}(7.2)$ & $5.12, \mathrm{t}(7.2)$ \\
\hline 16 & $1.67, \mathrm{~s}$ & $1.68, \mathrm{~s}$ & $1.66, \mathrm{~s}$ & $1.65, \mathrm{~s}$ & $1.65, \mathrm{~s}$ \\
\hline 17 & $1.79, \mathrm{~s}$ & $1.79, \mathrm{~s}$ & $1.79, \mathrm{~s}$ & $1.80, \mathrm{~s}$ & $1.82, \mathrm{~s}$ \\
\hline \multirow[t]{2}{*}{18} & 4.89, br s & 4.95 , br s & 4.74, br s & $1.16, \mathrm{~s}$ & $1.50, \mathrm{~s}$ \\
\hline & $4.81, \mathrm{br} \mathrm{s}$ & 4.86, br s & & & \\
\hline 19 & $1.33, \mathrm{~s}$ & $1.12, \mathrm{~d}(7.2)$ & $1.24, \mathrm{~s}$ & $0.98, \mathrm{~d}(6.6)$ & $0.98, \mathrm{~d}(6.6)$ \\
\hline 20 & $1.61, \mathrm{~s}$ & $1.60, \mathrm{~s}$ & $1.60, \mathrm{~s}$ & $1.59, \mathrm{~s}$ & $1.59, \mathrm{~s}$ \\
\hline OAc & & & & & $1.94, \mathrm{~s}$ \\
\hline $6-\mathrm{OH}$ & $3.67, \mathrm{~d}(9.0)$ & Not observed & $4.35, \mathrm{~d}(3.6)$ & $2.92, \mathrm{~d}(6.6)$ & $3.15, \mathrm{~d}(7.2)$ \\
\hline 8-OH & $4.20, \mathrm{~s}$ & Not observed & & & \\
\hline $10-\mathrm{OH}$ & & & & $3.01, \mathrm{~s}$ & \\
\hline $11-\mathrm{OH}$ & $3.70, \mathrm{~s}$ & & $3.99, \mathrm{~s}$ & & \\
\hline
\end{tabular}

${ }^{a}$ The coupling constants $(J)$ are in parentheses and reported in $\mathrm{Hz}$; chemical shifts are given in ppm; ${ }^{b} 500 \mathrm{MHz} ;{ }^{c} 600 \mathrm{MHz}$; 6 and 8-10, recorded in acetone- $d_{6} ; 7$, recorded in $\mathrm{CDCl}_{3}$. 
Table S2. ${ }^{13} \mathrm{C}$ NMR Data for compounds 6-10 ${ }^{a}$.

\begin{tabular}{|c|c|c|c|c|c|}
\hline no. & $\mathbf{6}^{b}$ & $7^{c}$ & $\mathbf{8}^{c}$ & $\mathbf{9}^{c}$ & $10^{c}$ \\
\hline 1 & $47.6, \mathrm{CH}$ & $47.4, \mathrm{CH}$ & 46.7, $\mathrm{CH}$ & $51.2, \mathrm{CH}$ & $52.4, \mathrm{CH}$ \\
\hline 2 & 34.7, $\mathrm{CH}_{2}$ & $35.8, \mathrm{CH}_{2}$ & $34.4, \mathrm{CH}_{2}$ & $33.5, \mathrm{CH}_{2}$ & $33.5, \mathrm{CH}_{2}$ \\
\hline 3 & $123.7, \mathrm{CH}$ & $124.0, \mathrm{CH}$ & $124.0, \mathrm{CH}$ & $123.4, \mathrm{CH}$ & $123.1, \mathrm{CH}$ \\
\hline 4 & $143.3, \mathrm{C}$ & $142.0, \mathrm{C}$ & $142.8, \mathrm{C}$ & $144.2, \mathrm{C}$ & $144.0, \mathrm{C}$ \\
\hline 5 & $61.9, \mathrm{CH}$ & $58.4, \mathrm{CH}$ & $61.2, \mathrm{CH}$ & $53.3, \mathrm{CH}$ & $53.2, \mathrm{CH}$ \\
\hline 6 & $75.2, \mathrm{CH}$ & $72.6, \mathrm{CH}$ & 74.6, CH & $75.1, \mathrm{CH}$ & $75.0, \mathrm{CH}$ \\
\hline 7 & $51.4, \mathrm{CH}$ & $52.0, \mathrm{CH}$ & $49.2, \mathrm{CH}$ & $50.1, \mathrm{CH}$ & $50.3, \mathrm{CH}$ \\
\hline 8 & $70.9, \mathrm{CH}$ & $69.0, \mathrm{CH}$ & 22.4, $\mathrm{CH}_{2}$ & 20.6, $\mathrm{CH}_{2}$ & $20.3, \mathrm{CH}_{2}$ \\
\hline 9 & 48.6, $\mathrm{CH}_{2}$ & 45.4, $\mathrm{CH}_{2}$ & 41.4, $\mathrm{CH}_{2}$ & $47.9, \mathrm{CH}_{2}$ & $41.1, \mathrm{CH}_{2}$ \\
\hline 10 & $150.3, \mathrm{C}$ & 147.6, C & $153.7, \mathrm{C}$ & $72.0, \mathrm{C}$ & $84.9, \mathrm{C}$ \\
\hline 11 & $76.2, \mathrm{C}$ & $34.0, \mathrm{CH}$ & 76.3, C & $35.7, \mathrm{CH}$ & $35.6, \mathrm{CH}$ \\
\hline 12 & 41.7, $\mathrm{CH}_{2}$ & 35.6, $\mathrm{CH}_{2}$ & $41.9, \mathrm{CH}_{2}$ & 35.6, $\mathrm{CH}_{2}$ & $35.6, \mathrm{CH}_{2}$ \\
\hline 13 & $23.7, \mathrm{CH}_{2}$ & $26.7, \mathrm{CH}_{2}$ & $24.0, \mathrm{CH}_{2}$ & 26.3, $\mathrm{CH}_{2}$ & $26.4, \mathrm{CH}_{2}$ \\
\hline 14 & $126.0, \mathrm{CH}$ & $124.7, \mathrm{CH}$ & $125.7, \mathrm{CH}$ & $126.1, \mathrm{CH}$ & $126.0, \mathrm{CH}$ \\
\hline 15 & $131.3, \mathrm{C}$ & $131.8, \mathrm{C}$ & $131.5, \mathrm{C}$ & 131.1, C & 131.1, C \\
\hline 16 & $25.8, \mathrm{CH}_{3}$ & $25.7, \mathrm{CH}_{3}$ & $25.8, \mathrm{CH}_{3}$ & $25.9, \mathrm{CH}_{3}$ & $25.9, \mathrm{CH}_{3}$ \\
\hline 17 & $15.8, \mathrm{CH}_{3}$ & $14.9, \mathrm{CH}_{3}$ & $16.1, \mathrm{CH}_{3}$ & 16.7, $\mathrm{CH}_{3}$ & $16.7, \mathrm{CH}_{3}$ \\
\hline 18 & $110.1, \mathrm{CH}_{2}$ & $112.1, \mathrm{CH}_{2}$ & $107.3, \mathrm{CH}_{2}$ & $30.5, \mathrm{CH}_{3}$ & $26.2, \mathrm{CH}_{3}$ \\
\hline 19 & $26.2, \mathrm{CH}_{3}$ & $18.5, \mathrm{CH}_{3}$ & $25.7, \mathrm{CH}_{3}$ & $17.7, \mathrm{CH}_{3}$ & 17.7, $\mathrm{CH}_{3}$ \\
\hline 20 & $17.7, \mathrm{CH}_{3}$ & 17.7, $\mathrm{CH}_{3}$ & $17.7, \mathrm{CH}_{3}$ & 17.7, $\mathrm{CH}_{3}$ & 17.7, $\mathrm{CH}_{3}$ \\
\hline \multirow[t]{2}{*}{ OAc } & & & & & $170.4, \mathrm{C}$ \\
\hline & & & & & $22.4, \mathrm{CH}_{3}$ \\
\hline \multicolumn{6}{|c|}{$\begin{array}{l}{ }^{a} \text { The assignments were based on } \mathrm{HMQC}, \mathrm{HMBC} \text {, and } \mathrm{COSY} \text { spectra; }{ }^{b} 125 \mathrm{MHz} ;{ }^{c} 150 \mathrm{MHz} ; \mathbf{6} \\
\text { and } \mathbf{8 - 1 0} \text {, recorded in acetone- } d_{6} ; \mathbf{7} \text {, recorded in } \mathrm{CDCl}_{3} \text {. }\end{array}$} \\
\hline
\end{tabular}


Table S3. DNA sequence of the alga specimen (Dictyota sp. nov.)

Ribulose-1,5-bisphosphate carboxylase/oxygenase large subunit gene (rbcl) of the alga specimen (Dictyota sp. nov.)

TTTATTACAGCCTGCGACATTTATAGAGCAAAAGCTTATCGAGTAGATCCAGTACCTGGAA CAAATGATCAATTTTTTGCATATATCGCATATGAATGTGATTTATTCGAAGAAGGTTCATT AGCAAATTTAACAGCATCAATTATTGGTAACGTTTTTGGTTTTAAAGCTGTTAAGGCATTA CGTTTAGAAGATATGAGAATTCCATTCGCATATTTAAAAACATTCCAAGGTCCTGCTACAG GGGTTATTGTAGAAAGAGAAAGATTAGATAAATTTGGGCGTCCTTTATTAGGTGCTACAGT TAAACCAAAGTTAGGTCTTTCTGGTAAAAACTATGGTCGTGTTGTTTATGAAGGTTTACGC GGTGGATTAGACTTCTTAAAAGATGATGAGAACATTAATTCACAACCATTTATGCGTTGGA AAGAACGTTTTCTATACTGTATGGAAGGTGTAAACCGTGCTGCTGCTGCTACAGGTGAGGT TAAAGGATCATATCTTAATGTAACAGCTGCAACAATGGAAAATATGTACGAACGTGCAGA TTATGCAAACTCTTTAGGTACAGTTATTGTTATGATCGATTTAGTTATTGGTTATACAGCTA TTCAAACAATGGCAATCTGGGCAAGAAAAGCTCAAATGATTTTACATTTACATCGTGCAG GAAATTCAACATATGCACGTCAAAAAAATCATGGTATTAATTTCCGTGTAATTTGTAAATG GATGCG. 